NBER WORKING PAPER SERIES

\title{
DOES COMPETITION FROM HMOS \\ AFFECT FEE-FOR-SERVICE \\ PHYSICIANS?
}

Laurence C. Baker

Working Paper No. 4920

\section{NATIONAL BUREAU OF ECONOMIC RESEARCH 1050 Massachusetts Avenue \\ Cambridge, MA 02138 \\ November 1994}

This paper is based on the second chapter of my Ph.D dissertation. An earlier version was circulated under the title "Do HMOs affect Fee-For-Service Physician Fees: Evidence based on county-level estimates of HMO market share." I wish to thank Joel Cantor, Kenneth Corts, Alan Krueger, and Uwe Reinhardt for helpful comments and discussions. I also thank Erika Miles iur her assistance. This paper is part of NBER's research program in Health Care. Any opinions expressed are those of the author and not those of the National Bureau of Economic Research.

(c) 1994 by Laurence C. Baker. All rights reserved. Short sections of text, not to exceed two paragraphs, may be quoted without explicit permission provided that full credit, including (C) notice, is given to the source. 


\title{
DOES COMPETTTION FROM HMOS \\ AFFECT FEE-FOR-SERVICE \\ PHYSICIANS?
}

\begin{abstract}
This paper develops county-level estimates of HMO market share for all counties in the United States and uses them to examine the relationship between HMO market share and the fee for a normal office visit with an established patient charged by 2,845 fee-for-service (FFS) physicians. Two-stage least squares estimates indicate that increases of 10 percentage points in HMO market share are associated with decreases of approximately 11 percent in the normal office visit fee. However, further examination indicates that the incomes of the physicians in the sample are not lower in areas with higher HMO market share. In addition, the quantity of services provided, measured by the number of hours worked and the number of patients seen per week, is not higher in these areas. While it is possible that physicians induce demand to change the volume or mix of services provided to patients in ways that do not affect the number of hours worked or patients seen, another hypothesis consistent with these findings is that FFS physicians respond to competition from HMOs by adopting multi-part pricing strategies in which the price for an office visit is reduced but prices for other services are raised.
\end{abstract}

Laurence C. Baker

Health Research and Policy

HRP Redwood Building, Room 253

Stanford University

Stanford, CA 94305

and NBER 


\section{Introduction}

An important form of competition in health care markets may take place between Health Maintenance Organizations (HMOs) and physicians who operate on a fee-for-service (FFS) basis. If HMOs compete with FFS physicians for patients, or if HMOs are able to provide medical care more cost-effectively, FFS physicians in markets where HMOs have significant market share may have to lower their fees or alter their practice styles to compete. A number of studies have examined the effects of HMOs on expenditures in the FFS sector. Some find that HMOs reduce FFS expenditures for ambulatory and hospital care expenditures,' while others suggest that HMOs have not reduced, and may actually have increased, costs. ${ }^{2}$ However, since all of these studies examine expenditures, which reflect both price and quantity, they are unable to separately determine the responses of price and quantity. There have been no studies looking directly at the relationship between HMOs and physician fees or the quantity or services provided. A clear understanding of health care markets requires that these potentially separate responses to HMO competition be examined. This paper examines the effects of HMO market share on the fees charged by FFS physicians and on the quantity of services they provide.

To do this, a good measure of HMO activity is needed. However, despite increases in the prevalence of HMOs and interest in their ability to provide cost effective medical care, estimates of HMO enroliment and market share have not been available for areas smaller than

\footnotetext{
'See e.g. Baker (1994), Robinson (1991), Noether (1988), survey by Frank and Weich (1985), and
ldberg and Greenberg (1979).

2See e.g. Hill and Wolfe (1993), McLaughlin (1988a and 1988b), Feldman et al. (1986), Luft et al.
6), and Newhouse (1985).
} 
states and selected Metropolitan Statistical Areas (MSAs). The next section of this paper (section 2) describes the development of new county-level estimates of HMO enrollment and market share. These estimates were constructed using published data that indicates, for the year 1990, the total enrollment for each HMO in the United States as well as the counties in its service area. The enrollees of each HMO were distributed to counties in the HMO's service area based on the county populations and distance from the HMO headquarters. The new estimates compare favorably to reliable estimates available for a limited number of MSAs.

Section 3 begins the examination of the effect of HMO market share on FFS physician prices by discussing the theoretical relationship between HMOs and FFS physician fees in the context of a simple linear spatial location model. In this model, as in standard competitive and monopolistically competitive models, the entry of HMOs into a market will cause FFS physicians to lower their prices. Thus, testing the relationship between HMOs and fees will provide information about the extent of competition in health care markets.

Section 4 presents the empirical work. The new estimates of HMO market share are used along with data on the fee for a normal office visit with an established patient from a 1991 survey of young physicians. Several results are of interest. First, the initial examination of the relationship between HMO market share and fees reveals an positive correlation--high HMO market shares are associated with expensive office visits. This is probably the result of HMOs choosing to locate in areas where physicians use high fees. To account for this possibility and for omitted variables that may cause market share to be endogenous, two-stage least squares (2SLS) was applied. Firm size and type (white collar vs. blue collar) serve as instruments for market share. The 2SLS results are in line with the predictions of the theory, 
showing that increases in HMO market share are associated with significant decreases in physician fees.

Among the independent variables included in the fee regressions are the number of generalist and specialist physicians per capita. These variables were used since earlier literature (e.g. Cromwell and Mitchell, 1986) indicated that increases in the number of physicians per capita are associated with increases in fees. However, the results presented here suggest that the number of physicians per capita does not have a significant effect on fees.

After examining fees I turn to incomes and the quantity of services provided. Here, 2SLS estimates reveal no relationship between HMO market share and physician incomes, the number of patients seen per week, the number of hours worked per year, and the number of surgical procedures performed. The fact that incomes did not change while fees fell would at first suggest that physicians induced demand to make up for the reduction in fees. However, the lack of a response in the other quantity variables suggests that this did not happen to a significant degree. An alternate interpretation is that physicians adjusted different fees in different ways, perhaps engaging in some sort of multi-part pricing scheme. For example, they may have lowered the office visit fee but raised fees other services in response to competition. 


\section{County Level Estimates of HMO Enrollment and Market Share}

To enable the subsequent empirical analysis, county-level ${ }^{3}$ estimates of HMO market share had to be developed. Conceptually, this took place in three steps. First, the total enrollment of each HMO in the country and its service area, specified by county, were obtained. Second, the enrollment of each HMO was distributed among the counties in its service area. Finally, the total number of enrollees in each county was computed by summing county enrollments over all of the HMOs serving the county. Using the total number of HMO enrollees in each county, HMO market share was computed simply as the ratio of enrollees to total population.

\subsection{Enrollment and Service Area Data}

The primary source of information on HMO enrollments and service areas is the National Directory of HMOs, published annually by the Group Health Association of America (GHAA). Each year the GHAA conducts a mail survey, with telephone follow up, of all known HMOs in the country and, among other things, asks their total enrollment and their service area. The results of the survey are published in the National Directory of HMOs (Hereinafter the Directory). To construct estimates of 1990 county market share, I used the

\footnotetext{
${ }^{3}$ Counties were selected as the unit of analysis since they represent areas small enough to capture market dynamics while retaining data availability. Counties are defined here using the Area Resource File (ARF) definitions. Although these are largely consistent with the standard FIPS definitions, they differ in a couple of ways. See ARF user documentation for details (Office of Health Professions Analysis and
Research, 1993).
} 
1991 Directory, which lists enrollment and service area for each of the $567^{4} \mathrm{HMOs}$ in the mainland U.S., Alaska, and Hawaii as of December 31, 1990.

In the Directory, enrollment is defined as all individuals who have been enrolled in the HMO as subscribers or as eligible dependents of subscribers and for whom the HMO has accepted the responsibility for the provision of basic health services. HMOs were asked to include enrollment by individuals and through employer groups, Medicare, Medicaid, and the Federal Employees Health Benefits Program. Any enrollment in Preferred Provider Organizations is excluded (GHAA, 1991). All but one of the HMOs in the directory indicated their enrollment. In the one missing case, data from the 1992 Directory was used. In all, there were about 36.4 million HMO enrollees in 1990.

For each HMO, the Directory also lists a service area. Most HMOs (459 of 567) indicated the counties that they served. ${ }^{5}$ However, the remaining 108 HMOs (19 percent), representing 20 percent of nationwide HMO enrollment, did not provide a clear definition of their market area in terms of counties. For these HMOs, the market area was determined by one of three methods. First, some ambiguous service area definitions did provide sufficient information to construct the service area in terms of counties. For example, an HMO that indicated serving "ten counties in metro Chicago" would have been assigned the ten counties that make up the Chicago Consolidated MSA (CMSA).

'The directory covers 569 HMOs, which includes 2 HMOs in Guam.

SIn one case, 3 HMOs operating in separate states but from the same headquarters indicated separate enrollment figures for each HMO but oniy one comprehensive market area. In this case, the market area list was separated and the operations in each state were treated independently. 
However, most of the ambiguous area definitions required further follow-up. In these cases, the next method used was consultation of the 1992 or 1993 Directories. Over time, the service area definitions included have become more precise. Many HMOs for whom the service area definition was ambiguous in 1991 provided specific county information for the more recent years. Where available, this information was used, with preference given to the 1992 rather than the 1993 Directory.

Since service areas change over time, use of the more recent information could distort the market areas. However, this is unlikely to cause significant bias in the estimates since, in most cases, there is considerable agreement between the definitions provided for different years. For example, in the 1991 directory, some HMOs indicated serving an area consisting of some number of counties in a state (e.g. "11 counties in southeastern Indiana.") In subsequent directories, most of these HMOs indicated their service area in a list of counties of approximately the right length. ${ }^{6}$ Other HMOs indicated only city names in the 1991 directory, but provided a list of counties encompassing the same cities in a later directory.?

After applying the first two methods, all but five of the 108 original ambiguous cases had been resolved. The remaining five HMOs were telephoned and a list of counties obtained.

"There was, of course, some variation. For example, an HMO that indicated serving " 54 counties" in 1991 listed only 48 counties in subsequent directories. An HMO that indicated " 31 counties" in 1991 listed 33 later. Since it is unclear whether the earlier or later definition is more accurate, the precise definitions available in the later directories were used.

'In the few cases where there was clear disagreement between the areas indicated in the 1991 National Directory and the county list provided in later directories, the county list was altered to conform to the
1991 information. 


\subsection{Distributing enrollment over service areas}

The next step was to allocate each county in the service area of an HMO a portion of the HMO enrollment that, in the case of the basic estimates, varies with the population of the county and, in the case of later estimates, incorporates the distance of the county from the HMO headquarters.

\subsubsection{Method A}

Estimates that depend only on county population (method A) were constructed first. For each HMO, method A gives to each county in the service area a number of enrollees proportional to that county's share of the total population in the service area. Specifically, consider HMO $i$, which has $E_{\mathrm{i}}$ enrollees and serves $N_{\mathrm{i}}$ counties. For each county $j$ in the service area, method $\mathrm{A}$ assigns enrollment, $a_{\mathrm{i}, \mathrm{j}}$, according to

$$
a_{i j}=\left(P_{j} / \sum_{k=1}^{N_{1}} P_{k}\right) E_{i}
$$

where $P_{\mathrm{j}}$ is the population in county $j$. Once the enrollment of each HMO has been distributed among the counties in its service area, the total enrollment for each county, $A_{j}$, is computed as

$$
A_{j}=\sum_{i} a_{i j}
$$

Using the set of county enrollment estimates, $A_{\mathrm{j}}$, market share estimates $S_{\mathrm{j}}^{\mathbf{2}}$ are computed by taking the proportion of the population enrolled in HMOs: $S_{j}^{a}=A_{j} / P_{j}$. The set of enrollment and market share estimates based on method A will be referred to as Series A. 


\subsubsection{Methods $B$ and $C$}

While series $A$ is probably a good first estimate of market share, it may be possible to improve the estimates by incorporating more information. One useful addition may be distance from HMO headquarters. If HMO enrollment is concentrated near the headquarters or if HMOs are likely to locate their headquarters in areas where their enrollment is concentrated, allocating more enrollment to counties closer to the headquarters will yield a better estimate.

Methods B and C use this strategy, apportioning enrollment using weights that are the product of a distance component and the county share of the service area population. Specifically the weight for county $j$ in the service area of HMO $i, w_{\mathrm{i}, j}$, is defined by:

$$
w_{i j}=d_{i j}\left(P_{j} / \sum_{k=1}^{N_{i}} P_{k}\right)
$$

where $d_{i, j}$ is the distance component of the weight.

The distance components vary with distance from the HMO headquarters. They are obtained from a function that declines linearly from 1 to 0.5 as distance from headquarters increases from 0 up to a set limit, $l$, and then becomes flat at 0.5 for all distances higher than l. Thus, $d_{i, j}$, is computed as:

$$
d_{i j}=\max ((2 l-\delta) / 2 l, 0.5)
$$


where $\delta$ is the distance from the centroid of county $j$ to the centroid of the county containing the headquarters of HMO $i$, calculated using the distance formula. ${ }^{8}$ Use of this function is admittedly ad hoc. It was chosen after experimenting with several different specifications, including non-linear functions and cut-off levels other than 0.5 , and observing that use of other plausible functional forms made little difference in the outcomes.

Methods $B$ and $C$ both use distance components based on equation (4), but differ in the limit $l$. The limit for method B is approximately 100 miles $^{9}-$ that is, method B distance components decrease from 1 to 0.5 as distance goes from 0 to 100 miles from the headquarters and are 0.5 for all counties more than 100 miles from the headquarters. The limit for method $\mathrm{C}$ is about 50 miles. Thus, method $\mathrm{C}$ concentrates enrollment near the HMO headquarters to a greater degree than method $\mathrm{B}$.

After scaling the weights so that they sum to one for each HMO, enrollment estimates for each county in the service area of each $\mathrm{HMO}, b_{i, j}$ and $c_{\mathrm{i}, j}$, were computed by multiplying the appropriate weight by the total enrollment in the HMO, $E_{\mathrm{i}}$. County level enrollment estimates, $B_{\mathrm{j}}$ and $C_{\mathrm{j}}$, as well as market share estimates $S_{\mathrm{j}}^{\mathrm{t}}$ and $S_{\mathrm{j}}^{\mathrm{c}}$, are computed as described

\footnotetext{
${ }^{8}$ Latitude and longitude population centroids for each county in the U.S. was obtained from the 1990 census county-level summary files.

${ }^{9}$ For convenience, distances are discussed in miles. The calculations, however, are done in degrees of latitude and longitude. For conversion, it is useful to assume that 1 degree is approximately equal to 50 mile, although conversion cannot be done exactly since longitude measurements are complicated by the curvature of the earth. The further north a measurement is made, the fewer miles are associated with a degree of longitude. The distortion introduced between the southern and northern U.S. is not large enough to introduce significant bias into the estimates. Alaska is not a problem since it is treated as a single unit and since there were no HMOs there in 1990.
} 
above for method A. The set of enrollment and market share estimates obtained from methods $\mathrm{B}$ and $\mathrm{C}$ will be referred to as series $\mathrm{B}$ and series $\mathrm{C}$.

Series B market share estimates are presented graphically in Figure 1. As expected, areas with the strongest concentrations of HMOs include: San Francisco, California; Portland, Oregon; Denver and Colorado Springs, Colorado; Minneapolis-St. Paul, Minnesota; Milwaukee, Wisconsin; and Rochester, New York. Other areas where HMOs have large market shares include: Los Angeles, California; Phoenix and Tucson, Arizona; Albuquerque, New Mexico; and Boston, Massachusetts. There are large areas in the midwest and south that had very little HMO activity.

Series $\mathrm{B}$ and $\mathrm{C}$ are highly similar to series $\mathrm{A}$, although there is some evidence that the later methods consolidated enrollees into metropolitan areas in which many HMOs are headquartered. Table 1 presents the correlations between the series A, B, and C estimates of enrollment (top panel) and market share (bottom panel). The series exhibit a high degree of internal consistency. For the enrollment estimates, in every case the correlation coefficients are above 0.99 . For market shares, the results of the different methods are also highly correlated, with coefficients of about 0.98 and higher.

\subsection{Validity of the new estimates}

Since the county service areas on which the series are based are quite accurate, it is likely that the series themselves are also quite accurate. Indeed, the nationwide pattern seen in Figure 1 is consistent with the expected patterns of HMO activity. However, it is also likely that some errors are present in the estimates. In particular, it is possible that too many 
enrollees were allocated to counties adjacent to metropolitan areas. Since many HMOs tend to serve metropolitan populations, counties which are partly metropolitan may be included in the service area of an HMO but may not, in actuality, be fully served. Since the apportionment algorithms use the entire population of the county when distributing enrollees, such counties may receive excess enrollees. For example, in Colorado, Teller and Crowley counties have the highest estimated HMO market shares in the state. These counties are adjacent to, but not included in, the Colorado Springs and Pueblo MSAs.

Since there have been no previous studies of county-level patterns in HMO enrollment, it is difficult to find existing data with which to validate the new measures. One exercise is possible at the MSA level. The GHAA has constructed estimates of enrollment and market share at the MSA level for the 27 largest MSAs in 1989 and the 54 largest MSAs in 1991 (see Palsbo, 1990; and Bergsten and Palsbo, 1993, respectively). Since my estimates are for 1990 , it may be helpful to compare the two sets of GHAA estimates to MSA estimates constructed by aggregating my data. ${ }^{10}$

Results of this exercise are presented in Table 2. The top panel shows mean enrollments and market shares. The two columns present means for the 27 MSAs and 54 MSAs for which the GHAA produced 1989 and 1991 estimates, respectively. My enrollment estimates are higher than the 1989 GHAA enrollment estimates and lower than the 1991

\footnotetext{
${ }^{10}$ Using my data, I constructed enrollments and market shares for MSAs that matched those used by the GHAA as closely as possible. However, MSAs in New England are not always defined by counties. To construct estimates for these MSAs, I attempted to group counties to match the exact definitions. However, the geographic areas covered by the standard New England MSAs and my New England MSAs are not exactly the same. All estimates presented were reestimated without the New England MSAs and
no significant differences were found.
} 
enrollment estimates, which is to be expected since HMO enrollment was growing over this time period. For 1991 the difference in mean market share is consistent with the difference in mean enrollments. Curiously, in the 1989 samples the mean market shares obtained from my data are lower than the mean GHAA market share. This may be due to differences in the population estimates used. The population estimates used in my calculations are from the 1990 Census, while the GHAA used 1989 population estimates based on projections from the 1980 Census and Current Population Surveys.

The bottom panel of Table 2 shows the correlation between the GHAA estimates for 1989 (column 1) and 1991 (column 2) and the series A, B, and C enrollment and market share estimates. The enrollment estimates are very highly correlated--the correlation coefficients are above 0.99 in every case. The market share estimates are also highly correlated, with coefficients of about 0.97 for the 1989 sample and 0.94 for the 1991 sample."

\section{Theory of HMOs and FFS physician fees}

Before proceeding to an empirical examination of HMO market share and physician fees, this section considers theoretical frameworks within which physician prices may be examined. The question under consideration is the effect that the entry of HMOs into a market, or their expansion within a market where they already exist, will have on the fees charged by FFS physicians.

\footnotetext{
"In addition, I computed correlation coefficients weighting by the total population of the MSA. In all cases, these coefficients were higher than those reported in Table 2 . The correlation for the enrollment estimates based on series B was 0.995 for the 1989 sample and 0.997 for the 1991 sample. For market share estimates based on series B, the coefficients were 0.978 for 1989 and 0.967 for 1991 .
} 
The entry or expansion of HMOs in a market may be modelled in two ways. First, HMOs may be treated as new entrants into a market, bringing new physicians and resources into a market. Alternatively, they may be viewed as reorganizing existing physicians and resources already in place within the market. The implications of HMO entry under the former view can be addressed in the context of existing theories of physician pricing, which often examine the effect of the physician entry on prices. However, since the latter view may be more plausible for many health care markets, and since the existing models of physician pricing do not readily allow for heterogeneous consumers or products, I will also model physician prices using a spatial location model. Variation in the cost functions of providers will be incorporated into this model.

The traditional models of physician pricing have, for the most part, been developed in the context of the debate over supply-induced demand and are based on standard market frameworks. ${ }^{12}$ Perhaps the simplest case is that of a competitive market in which expansions in the supply of health care, perhaps occasioned by the entrance of an HMO from outside the market, will prompt prices to fall as the supply curve shifts out. However, if physicians have at least some market power, monopolistic competition may be a preferable framework. ${ }^{13}$ In this case, the market demand is divided among the physicians in the market, but each

\footnotetext{
"See, for example, Phelps (1992), chapter 7, or Feldstein (1988), chapter 9, for a more complete discussion.

${ }^{13}$ The markets in which physicians operate may be viewed as falling on a continuum running between competitive and monopolistic. Thus, the two models presented here may be viewed as opposite extremes. One way to implement such a continuum is by incorporating patient search. If there is no patient search then the model is monopolistic or monopolistically competitive. As more patients search, the model approaches the competitive outcome. See, for example, Pauly and Satterthwaite (1981) or Schwartz and Wilde (1982).
} 
physician still faces a downward sloping demand curve. If there are excess profits being earned in the market, then profitable entry by new providers is possible. The entrance of a new provider will reduce the demand available to each provider, shifting their demand curves in and causing prices to fall.

The implications of these models are less clear if physicians can induce demand for their services. ${ }^{L t}$ If they are able, they may do so in response to changes in supply and demand conditions. This may upset the conclusions derived under the assumption that there is no demand inducement. For example, under the target income hypothesis ${ }^{15}$ a supply increase that leaves physicians below their target level will be met with an induced outward shift in the demand curve. This will, at least, result in a smaller reduction in prices than would have occurred without demand inducement and, depending on how much demand physicians can and wish to induce, could shift the demand curve far enough to cause prices to rise. ${ }^{16}$

Although the models discussed above are useful for describing the effects of additional physicians, they do not incorporate aspects of the marketplace that are important when working with HMOs. Three things are particularly noteworthy. First, the standard models orien assume that both the consumers and the product are homogeneous. ${ }^{17}$ However, it is

\footnotetext{
${ }^{1+}$ Whether physicians are able and willing to induce demand for their services is the subject of considerable debate. See, for example, Reinhardt (1985) or Feldman and Sloan (1988) for discussions of this issue. Cromwell and Mitchell (1986) and McCarthy (1985) are examples of opposing empirical evidence.

${ }^{15}$ The target income hypothesis posits that physicians attempt to meet a target income. If their income falls below the target level, they will undertake action, possibly including demand inducement, to bring their income back up to the target. It was originally posited in Evans (1974); See Feldstein (1988) pages 189-192 for a nice review.

${ }^{16}$ For further discussion of the ambiguity surrounding price results when supply induced demand is possible, see Feldman and Sloan (1988).
} 
likely that HMOs and FFS physicians produce health care in somewhat different ways and that consumers vary in their preferences for medical care--some consumers may be more favorably disposed toward receiving care in a FFS setting than others. Second, the standard models assume that all providers face the same cost of providing health care services. However, if HMOs can provide health care services more cost-effectively than FFS physicians, as is often suggested, this assumption will not hold. Third, the standard models assume that entry takes place in the form of providers new to the market. However, much of the recent growth in HMOs has come from the formation of networks by providers already established within their markets. In other markets, existing HMOs are working to expand their operations by recruiting local physicians to join them or by purchasing their practices.

Use of a simple linear spatial location model of the type originally introduced by Hotelling $(1929)^{18}$ is one way to incorporate these aspects of the market. This model assumes that the consumers of health care in a market are uniformly distributed on the unit interval. The interval represents a continuum of styles of health care provision and the location of consumers on the interval reflects the degree to which they prefer FFS care, which will be assumed to be at 0 , or HMO care, assumed to be at $1 .{ }^{19}$ FFS providers and HMOs produce a

\footnotetext{
17 In some cases, models have been extended to allow for variation in quality among providers. See, for example. Feldman and Sloan (1988).

${ }^{18}$ See Tirole (1988), chapters 2 and 7 . for a discussion of this model.

${ }^{19}$ The assumption that FFS and HMO styles of care lie at the extremes of the interval simplifies the model. It is possible to derive many of the results shown here under the more general assumption that FFS and HMO care lie at arbitrary points within the interval.
} 
single good, "health care," but differ in the way in which they produce it. FFS physicians and HMOs have constant marginal cost: $c_{\mathrm{f}}$ and $c_{\mathrm{h}}$, respectively.

The consumers have unit demands for health care--they either consume 0 or 1 unit. They face costs of consumption that increase linearly with the distance from the type of health care consumed; that is, a person lying at point $x, x \in[0,1]$, would face $\operatorname{costs} t x$ if FFS care is consumed and $t(1-x)$ if HMO care is consumed, where $t>0 .{ }^{20}$ Consumers have reservation price $r$, which is assumed to be sufficiently high that the entire market is covered.

I examine this model in two stages. I begin with a market in which only FFS care is available and consider the effects of making HMO care available, holding the marginal cost of providing FFS care and HMO care equal. Next, I consider variation in marginal costs

Assume a single profit-maximizing FFS provider located at 0 on the continuum. This provider will face a demand curve that depends on the FFS price, $P_{r}$. Specifically, all consumers on the interval $[0, \bar{x}]$, will demand health care from the provider, where

$$
\bar{x}=\left(r-P_{f}\right) / t .
$$

The protit-maximizing price will be:

$$
P_{f}=(1 / 2)(c+r)
$$

where $c$ is the marginal cost for the FFS provider, which is assumed for now to be equal to the marginal cost for the HMO.

\footnotetext{
${ }^{30}$ In the standard version of this model, these costs are the transportation costs incurred by the consumers in travel to and from the point of purchase.
} 
Now, if an HMO enters the market, and locates at the other end of the continuum, it will compete for consumers with the FFS provider. Since both providers have the same marginal cost, it is easily shown (see Tirole, 1990, page 280) that the Nash equilibrium price charged by each will be equal and will be given by:

$$
P_{f}^{*}=P_{h}^{*}=c+t
$$

where $P_{\mathrm{h}}$ denotes the price charged by the HMOs and the stars distinguish the prices charged when both providers operate from the price charged when only FFS physicians operate. Comparing equations (6) and (7) shows that the FFS price falls after HMO entry $\left(P_{\mathrm{f}}^{*}<P_{\mathrm{f}}\right)$ if $c$ $+2 t<r$. This is equivalent to the condition that the entire market is covered by the FFS producer operating alone. That is, if HMOs and FFS providers compete for patients in the market, the entry of HMOs will force FFS providers to lower their price.

To extend this model, I now allow different marginal costs to face HMOs and FFS providers. It can then be shown (see Appendix A) that the FFS and HMO prices, $P_{f}$ and $P_{h}$, are given by:

$$
P_{f}=t+(2 / 3) c_{f}+(1 / 3) c_{k}
$$

and

$$
P_{h}=t+(2 / 3) c_{h}+(1 / 3) c_{f} .
$$


Equations (8) and (9) yield two important results. First, reductions in the cost of providing HMO care will reduce the FFS price. As the HMO cost falls, it becomes profitable for the HMO to attract additional consumers away from the FFS provider, which increases the level of competition. The second implication of equations (8) and (9) is that, if the HMO's marginal cost is less than the FFS providers, the HMO price will be lower than the FFS price. This is observed, to at least some extent, in the actual market.

Taken as a whole, this model shows that entry by an HMO into a FFS dominated market and a reduction in the cost of providing HMO care will result in a reduction in the FFS price. In addition, the second stage considered alone has a useful interpretation. Consider a model in which the definition of the continuum is broadened so that it represents, for example, the progression from high-technology, non-primary-care intensive medicine to more conservative, preventive-care-oriented medicine. Suppose that half of the producers in this market operate at one end and half at the other end. In this context, the model suggests that if the providers at one end band together to form an $\mathrm{HMO}$, and in doing so are able to reduce their marginal cost, they will force the physicians at the other end to reduce their prices. In this way, the result that the FFS price falls when HMOs are created does not depend on the assumption that new HMOs enter from outside the market.

So far, this model has only dealt with the implications of HMO entry or formation. However, it may also be possible to expand this model to include the effects of the expansion of existing HMOs through non-price competition. One way in which this could be viewed is as a shift in the distribution of consumers on the continuum. If HMOs are able to make 
consumers more favorably disposed toward the type of care they offer, they will force further price reductions by the FFS providers who will have to compete ever harder for patients.

The result that FFS prices will fall in response to the formation of HMOs becomes more complicated if FFS providers are able to induce demand. However, under some circumstances this result will continue to hold. In particular, as long as consumers are able to observe FFS and HMO prices and face relatively low costs of switching providers (so that neither provider has strong market power over their consumers) providers will only be able to raise prices at the expense of lost demand. Although they may be able to prescribe excess services or otherwise induce demand, price changes will be difficult. However, if providers do have market power over their consumers, then price increases may again become possible.

This model is meant to be instructive rather than comprehensive and there are some components of the health care system that are missing and should be noted. First, the implications of health insurance are not considered. Not only may traditional indemnity insurance distort the incentives facing patients, but the fact that HMOs offer a form of insurance which is often more generous than traditional policies but imposes additional constraints may also complicate analysis. Second, this model assumes that all patients have trif ability to choose between a FFS provider and an HMO. However, for employees this choice is likely to be constrained by the health insurance options offered by their employers. Thus, the incentives of employers as well as the premiums charged for insurance may be important. Finally, this model assumes that providers produce only a single good. However, taken as a whole, physicians provide thousands of goods and each may be independently priced. It is quite possible that some fees would respond differently to competition than 
others. For example, if some fees are focal for consumers when selecting a provider, physicians may reduce these fees but raise others in response to competition.

\section{An Empirical Examination of HMOs and Physician Fees}

\subsection{Data}

To empirically examine the relationship between HMOs and FFS physician prices, I combined the county level estimates of HMO market share described in section 2 with data on the fees and other characteristics of young physicians obtained from the 1991 Survey of Young Physicians. This survey was designed to represent all allopathic physicians (and osteopathic physicians completing allopathic residencies) who were under age 45 and had between 2 and 10 years of practice experience in $1991 ;^{21}$ it contains data for 6,053 physicians and had a response rate of 70 percent. Since the survey was based on a complex sampling design, weights are used to adjust for the sampling strategies used and correct estimates to reflect the AMA Physician Masterfile distribution of young physicians by sex, age, country of medical education (U.S. or other), and AMA membership. ${ }^{22}$

Additional characteristics of the county in which each physician reported having his or her main practice ${ }^{23}$ was obtained from two other sources and added to the file. Data on the

\footnotetext{
"See Cantor et al., 1993 for further information on this survey.

2:All results presented were also estimated without the weights. In no case did this qualitatively change any of the findings.

${ }^{23}$ Physician could list multiple practices on the survey. The analysis presented here focuses on the practice designated by the physician as the main practice. In this sample, 419 (14.7 percent) of the physicians reported having more than one practice.
} 
number of physicians and hospital beds, county economic conditions, and demographic characteristics were obtained from the 1993 Area Resource File, which compiles data from a variety of sources including the American Medical Association, the American Hospital Association, and the Bureau of the Census. The mean number of employees per firm was obtained from the 1990 County Business Patterns file.

To identify a base sample of FFS physicians for analysis, I initially selected the 3,928 physicians who answered "yes" when asked "In [your main] practice do you provide at least some medical care for which patients pay on a fee-for-service basis" and who indicated elsewhere that they were not employed by an HMO in their main practice. Physicians practicing FFS medicine who also have contracts with Independent Practice Association (IPA) type HMOs were included in the sample.

From this group, radiologists, anesthesiologists, and pathologists were excluded since physicians in these specialties were not asked to report their fees on the survey. Psychiatrists were also excluded, as were physicians for whom fees or other necessary information was unavailable. This left a sample of 2,845 physicians ( 47 percent of the original 6,053 ) for analysis. Physicians in the sample represent all 50 states and Washington DC, and 821 counties.

\subsection{Results}

Characteristics of the sample are described in Table 3. The top portion of the table shows mean fees and hourly incomes. The survey asked physicians "In [your main] practice, what is your current usual fee for an office visit with an established patient including an 
examination and/or treatment for the same or new illness?" This is a standard question, identical to the question asked yearly by the AMA on the annual Socioeconomic Monitoring System surveys, which most physicians should understand and be able to answer. In my sample, the mean fee was $\$ 46.25$. It is important to note that this fee pertains to only one of the many services that physicians provide. As discussed below, fees for different procedures may vary in different ways. Unfortunately, data that would allow me to examine this issue directly are not available.

Contrary to expectation, an initial examination suggests that physician fees are positively correlated with market share. The mean fee for physicians in counties without HMOs is $\$ 35.34$, while the mean fee for physicians in counties in which HMO market share is 25 percent or more was $\$ 53.09$. A simple regression of the log of physician fees on HMO market share and a constant confirms this finding. The estimated equation is:

$$
\log f=\begin{gathered}
3.563 \\
(0.015)
\end{gathered} \quad \underset{(0.008)}{0.097 S} \quad \mathrm{R}^{2}=0.05
$$

where $\log f$ denotes the natural logarithm of physician fees ${ }^{24}$ and $S$ denotes HMO market share (divided by 10 ). Standard errors of the coefficients are in parenthesis.

The bivariate analysis presented above suffers from at least two important difficulties. First, there are many omitted variables that may be correlated with both physician fees and HMO market share. For example, urban areas are more likely to have HMOs and may also have higher costs of living, which may prompt higher fees. A number of other factors

\footnotetext{
${ }^{2+}$ The logarithm of fees is used based on visual inspection and Box-Cox analysis. See the discussion of equation (12).
} 
including the preferences of physicians, patients, and insurers as well as the health status of the population could also play a role.

A second difficulty is the fact that HMO market share and fees are likely to be simultaneously determined. Forward-looking HMOs may consider current and expected future expenditures when deciding whether to enter or expand operations in a market. HMOs that can provide highly cost-effective care will achieve better outcomes in markets where FFS physician services are overpriced and may thus be more likely to enter or expand in these markets. Alternatively, demand for HMOs by purchasers of health coverage may be higher in areas with high expenditures since use of HMOs may be viewed as an effective cost containment measure. These hypotheses are supported by studies which report that managed care market share is positively related to overall health care costs and utilization. ${ }^{25}$

To incorporate additional independent variables into the analysis and attempt account for these difficulties, I adopt a two-stage least squares (2SLS) approach in which equations of the following form are estimated:

$$
\begin{array}{r}
S_{i}=\alpha_{0}+\alpha_{1} X_{i}+\alpha_{2} N_{i}+\eta_{i} \\
\log f_{i}=\beta_{0}+\beta_{1} \dot{S}_{i}+\beta_{2} X_{i}+\epsilon_{i} .
\end{array}
$$

Here, subscript $i$ denotes physician $i$. HMO market share in 1990 is denoted by $S$. Series B estimates of market share are used because of their marginally better performance in

\footnotetext{
${ }^{25}$ See e.g. Welch (1984), Morrisey and Ashby (1982), Goldberg and Greenberg (1981), McNeil and Schlenker (1975).
} 
validation. Results obtained using series $\mathrm{A}$ and $\mathrm{C}$ are almost identical to those reported. The natural logarithm of 1991 physician fees is denoted by $\log f$. A logarithmic specification for fees is used since both visual inspection and Box-Cox analysis indicated that it was superior to a linear specification. ${ }^{26} X$ denotes a vector of additional covariates. In some specifications, $X$ includes a set of 50 state dummies. $N$ denotes the excluded instruments. $\epsilon$ and $\eta$ are assumed to be well-behaved error terms.

A number of independent variables are used (see Table 3). In addition to HMO market share, several variables controlling for the characteristics of each physician and the area in which he or she practices are included. Included physician characteristics include specialty, practice setting, sex, board certification, location of medical school (U.S. or foreign), and age. A dummy variable indicating whether a physician has a contract with an IPA is also included. This variable is intended to capture the effects of the IPA on the remainder of the physicians practice. ${ }^{27}$ Finally, the number of patients seen per hour is also included as a measure of quality and patient satisfaction. Since, as discussed below, patients per hour may be related to HMO market share, models were reestimated without this variable and the results did not differ significantly from those reported.

\footnotetext{
${ }^{20}$ The Box-Cox transform of $y,\left(y^{2}-1\right) / \lambda$, indicates a log specification as $\lambda$ goes to 0 and a linear specification as $\lambda$ goes to 1 . Maximum likelihood estimates of $\lambda$ are 0.151 without state dummies included and 0.152 with them.

${ }^{27}$ This effect could go either way. On the one hand, FFS physicians with IPA contracts might carry over pricing practices from the IPA portion of their practice to the FFS portion to facilitate uniform office practices. On the other hand, if the IPA can obtain price concessions from physicians, they may price discriminate against their FFS patients to make up the lost revenue.
} 
Economic, demographic, and health system variables describe the area in which each physician practices. A dummy indicating whether the county is in an MSA is also used. Included economic characteristics are the unemployment rate and per capita income. Demographic characteristics include two variables indicating the percent of the population that has completed high school and college, and three variables indicating the percent of the population that is female, non-white, and over age 65 . Hospital capacity is included in the equations using the number of hospital beds per 1000 population.

Since other physicians are likely to provide an important source of competition, I include the number of generalists and specialists per 1000 population. ${ }^{28}$ Since generalist physicians may be substitutes for other generalist physicians while specialists may be complements, and vice versa, the number of generalists and specialists per 1000 population is interacted with dummy variables indicating whether the physician is a generalist or a specialist.

In equation (11), the average number of employees per firm and the percent of the work force that is white collar are the excluded instruments for HMO market share, $S$. These are appropriate instruments if they are correlated with $S$ and uncorrelated with $\epsilon$. Since I expect that larger firms and white collar firms are more likely to offer their employees a variety of health insurance options, which may include HMOs, areas with more of these types of firms will provide a better environment for HMOs.

\footnotetext{
${ }^{28}$ Generalists physicians are those in general/family practice, general internal medicine, and pediatrics. All other physicians are considered specialists.
} 
Results from estimation of the first stage (equation 11) are presented in Table 4. The regression presented in the first column does not include the state dummies; the regression presented in the second column does. In both cases, the excluded instruments (employees per firm and percent of workers white collar) have the expected sign and are highly statistically significant. Following the suggestion of Bound, Jaeger, and Baker (1993), I performed an F test for the hypothesis that the coefficients on the instruments are jointly 0 . The hypothesis was rejected in both specifications $(F[2,2808]=123.02$ in column 1 and $F[2,2758]=78.94$ in column 2).

Results from estimation of the second stage are presented in Table $5 .{ }^{29}$ Columns 1 and 2 contain OLS and 2SLS results from a specification that omits the state dummy variables, respectively. In the OLS model, the coefficient on HMO market share is positive, although not significantly different from zero. This represents a significant decline from the bivariate results reported earlier in equation (10). Closer examination of the independent variables indicates that those responsible for the majority of the decline are the health system variables (generalists and specialists per capita, hospital beds per capita), economic characteristics (unemployment rate and per capita income) and the MSA dummy. Use of only these independent variables reduces the coefficient on market share from 0.097 to 0.031 .

In the 2SLS results (column 2), the coefficient on market share is -0.108 and significant $(t=3.471)$. This suggests that the bias induced by the simultaneous determination

\footnotetext{
${ }^{29} \mathrm{OLS}$ standard errors are presented. However, to account for possible heteroskedasticity, I computed both White (1980) standard errors and a set of standard errors based on a generalization of White's method that allowed for intercorrelation between physicians in the same state. In neither case did this cause a qualitative change in the results.
} 
of HMO market share and FFS physician fees causes OLS results to understate the feereducing effect of HMOs. This result indicates that inereases of 10 percentage points in HMO market share are associated with decreases of 10.8 percent in FFS physician fees.

The coefficients measuring the effect of the number of physicians are not significantly different from zero. Although some studies (e.g. Cromwell and Mitchell, 1986) have found that fees increase with the number of physicians, and the OLS results indicate that fees are positively associated with the number of specialists per capita, the 2SLS results provide no evidence of a relationship between the number of physicians and fees. This result, which is consistent with the results of other studies that use physician level data (e.g. Rossiter and Wilensky, 1983), may indicate that physicians are not able to raise their fees in response to the entry of other physicians. Although it does not deal with the ability of physicians to induce their patients to use more services, this finding contradicts a portion of the supply-induced demand hypothesis

The use of both the mean number of employees per firm and the percent of workers who are white collar as instruments for market share provides an overidentifying restriction that can be tested. The test used here examines the hypothesis that both instruments used independently would produce the same estimate of the effect of managed care and is constructed by multiplying the sample size by the $R^{2}$ from a regression of the $2 S L S$ errors on the exogenous variables and excluded instruments (see Newey, 1985). The $\chi^{2}[1]$ test statistics 
are presented at the bottom of Table 5. The overidentifying restrictions are not rejected at the 0.01 level. $^{30}$

The difference between the OLS and 2SLS results suggests that endogeneity bias is present in the OLS estimates. More formally, a Hausman (1978) test, formulated by estimating equation (7) with both the predicted values of market share from the first stage and the actual values, rejects the hypothesis that the difference in market share is uncorrelated with the error term $(t=4.204)$.

It is not clear that state dummies should be included in the equations. For example, if HMO market shares are high in all of the counties of a state, the dummy for that state will absorb any effect of HMO market share on fees. However, since there is also the possibility that the specifications presented in columns 1 and 2 of Table 5 omit important effects that might be picked up by state dummies, they are included in the specifications presented in columns 3 and 4 . Column 3 presents OLS results and column 4 presents 2 SLS results. With the additional variables, the OLS estimate falls slightly and remains insignificant. The 2SLS estimate falls somewhat $(\beta=-0.077)$, but the standard error almost doubles and the t-statistic falls to 1.361 .

Because HMOs employ mostly generalisı physicians and tend to provide a large amount of primary care, they may affect the fees of generalists and specialists differently. Changes in both demand for health care and supply of physician services may play a role. On the demand

\footnotetext{
${ }^{30}$ Analysis using the instruments separately indicates the average number of employees per firm does most of the work. The estimate of the effect of HMO market share obtained using just this instrument is similar to that reported while the estimate obtained using only the percent of workers who are white collar is much smaller and statistically insignificant.
} 
side, if HMOs attract those patients who are most interested in obtaining regular primary care ${ }^{31}$ generalist physicians who would have provided this care may feel pressure. Specialists, on the other hand, might not be pressured since HMOs are not as likely to attract patients seeking specialty care. The supply relationship may work in the opposite direction. Since HMOs tend to hire more generalists than specialists, and often hire them out of the FFS sector, markets with many HMOs may have fewer FFS generalists practicing in them than specialists. This may allow FFS generalists to charge higher fees.

To examine this question more closely, I estimated equations (11) and (12) using 2SLS separately for generalists and specialists. ${ }^{32}$ The coefficients obtained for HMO market share and the number of generalists and specialists per capita are presented in Table 6 . Coefficients obtained on other variables were similar to those reported in Table 5. The first column excludes the state dummies and the second column includes them. For both generalists and specialists, the effect of HMO market share is negative and significant when the state dummies are excluded $(\beta=-0.108, t=2.775$ for generalists, $\beta=-0.083 t=1.779$ for specialists). As in Table 5, however, once the state dummies are added the coefficient is no longer statistically significant. In addition, as in Table 5, the coefficients for the number of generalists and specialists per capita provide no evidence that fees are related to the number of physicians in the market.

\footnotetext{
${ }^{31}$ There is evidence that HMOs attract a patient mix that is healthy relative to the overall population. See e.g. Luft and Miller (1988) or Wilensky and Rossiter (1986).

${ }^{32}$ As before, generalist physicians are those in general/family practice, general internal medicine, and pediatrics. All others are specialists.
} 
One interpretation of the fact that the coefficient on market share in the equation for generalists is somewhat larger than the coefficient in the equation for specialists is that the effects of HMOs on demand are felt more by generalists than specialists, and that the influence of demand factors over physician prices is stronger than the effects of HMOs on the relative supply of generalist and specialist physicians. However, the fact the difference between the coefficients is not large ${ }^{33}$ suggests that interpretations should be made with caution.

\subsection{Physician Incomes}

Although one might expect that physician incomes should fall if the fee for a standard office visit falls, this need not happen if physicians are able to do one or more of the following things. First, physicians may be able to respond to a reduction in the fee for a standard office visit by increasing the quantity of services provided. This is the standard contention of the supply-induced demand hypothesis. A related possibility is that physicians can alter their casemix, perhaps through demand inducement, toward services with larger markups. Finally, it may be possible to raise the fees for other services enough to compensate for the reduction in the office visit fee.

To examine these questions empirically, I estimated models identical to those used above (equations 11 and 12) using the log of physicians hourly incomes as the dependent variable. ${ }^{34}$ Hourly income estimates were derived from data on yearly income, weeks of

\footnotetext{
${ }^{33}$ The difference is statistically significant. An F test for the equality of the two coefficients rejects the hypothesis $(\mathrm{F}[1,2788]=7.609)$.

${ }^{34}$ Models using weekly and yearly income yielded highly similar results.
} 
work, and number of hours worked per week for each physician. On the survey, most physicians reported their 1990 yearly income after expenses but before taxes. ${ }^{35}$ To compute hourly income, yearly income was divided by the product of the number of weeks worked in 1990 and the number of hours worked per week. The number of weeks worked during 1990 was reported by each physician. The number of hours worked per week is proxied by the number of hours worked in the last complete week of practice prior to the survey. In my sample, mean hourly earnings are $\$ 54.35$.

Selected coefficients from 2SLS estimation of the models are presented in Table 7. As above, the model presented in the first column excludes the state dummies and the model in the second column includes them. In neither case is the coefficient on HMO market share significantly different from zero--changes in HMO market share are not associated with changes in physician incomes.

\subsection{Quantity of Services Provided}

Perhaps physicians are working more in response to the reduction in fees. To see whether this is the case, I looked at the number of patients each physician reported seeing in the most recent full week of practice and the number of hours worked in the previous year. Regression results are presented in Table 8 . There is no evidence that physicians increase the number of patients they see in response to competition from HMOs (columns 1 and 2). If

\footnotetext{
${ }^{35}$ Specifically, the survey asked for "all income from fees, salaries, retainers, bonuses, and other forms of compensation" after expenses but before taxes. Contributions to pension, profit-sharing, or other deferred compensation plans are excluded. For 99 of the physicians yearly income had to be imputed from two other questions, one asking what each physician thought an appropriate income for someone like himself or herself might be and a second asking the relationship between the actual and appropriate figure.
} 
anything, the estimates indicate that they see fewer patients. Results from regressions where annual hours worked is the dependent variable (columns 3 and 4) also failed to show a significant relationship, although the estimated coefficients were positive. The final two columns of Table 8 examine the number of patients seen per hour. A log specification is used since the distribution of the number of patients per hour is highly skewed. The estimated coefficients are negative but not significantly different from zero.

As an additional test, I examined the number of surgeries that general and family practitioners, general internists, surgeons, obstetricians, and gynecologists, performed or assisted with in the previous week of practice. ${ }^{36}$ The results are presented in Table 9. Although the coefficients on HMO market share are positive, they are insignificant and provide little evidence of a quantity response.

Taken together, these estimates provide no evidence that physicians take on more patients, work more hours or see more patients per hour in response to competition from HMOs. The findings for the number of surgeries performed provides limited evidence that they do not perform extra services. A common response of health economists to the phenomena of falling fees and stable incomes would have been to suggest inducement of demand by physicians. However, these findings imply that the maintenance of physician incomes in the face of a decline in the basic office visit fee has not occurred because physicians have suggested extra office visits to patients or performed extra procedures for them in the office (to the extent that this would have increased their hours of work). It is

\footnotetext{
${ }^{36}$ Only physicians in these specialties were asked to report the number of surgeries on the survey.
} 
possible that physicians have altered the service mix they provide to patients toward services with higher mark-ups. However, the extent to which this is possible without changing hours worked is probably limited.

Another explanation is that physicians are able to adjust prices for different services in different ways--engaging in two-part (or multi-part) pricing. For example, they may raise the margin on X-rays while lowering office visit fees. This may be an effective response to competition if those selecting physicians are able to look at fees for only a few of the many services that physicians provide. Alternatively, physicians may adjust fees to target patients for whom they are competing with HMOs. If these patients are more interested in office visits than other services then this strategy may be optimal. Since some literature has shown that HMOs attract relatively healthy patients, an optimal response to competition may be to reduce the prices for services of interest to these patients--office visits, common procedures, and preventive care--while raising the prices of interest to other patients who, because they are not tempted to join HMOs, have less elastic demand. ${ }^{37}$

\subsection{Physician Density and Quantity of Services}

Tables 7,8 , and 9 also present coefficients for the number of physicians per capita. Overall, they do not indicate that the number of physicians per capita affects physician incomes or the quantity of services provided. This contrasts with earlier supply-induced

\footnotetext{
${ }^{37}$ See Hoerger (1989) for an example of a model of two-part pricing examining the prices for new and established patient office visits.
} 
demand literature that suggests that physicians would increase quantity in response to an increase in the number of physicians in their market.

\section{Conclusion}

Examination of the relationship between HMO market share and physician incomes shows that increases in market share are associated with decreases in fees. Although simple OLS estimates of the effect of HMO market share were positive--increases in market share are associated with increases in fees--2SLS estimates indicate that increases in HMO market share of ten percentage points are associated with decreases of 10.8 percent in FFS physician fees. The explanation for the disparity between the OLS and 2SLS results may be the presence of simultaneity bias. If HMOs are more likely to locate in areas where fees are higher, then the positive association observed in the OLS regressions may be the result of this bias.

However, examination of the relationship between HMO market share and physician incomes did not reveal a significant association. Furthermore, the number of patients seen, the number of hours worked, and the number of surgeries performed were not significantly related to HMO market share. There are at least two explanations for the ability of physicians to maintain their incomes while at least one fee is falling. First, they may be adjusting different fees in different ways: If the fee for an office visit falls, but fees for other services can be increased to make up for the change, incomes may not fall. Second, physicians may be able to alter the mix of services provided to patients toward services with higher margins and thus maintain incomes. The fact that data necessary for a direct exploration of these hypotheses are unavailable provides a useful direction for furure efforts. 
Overall, while the findings from the fee analysis suggest that competition from HMOs is able to affect the fee for at least one service, the rest of the findings suggest that physicians retain a non-negligible amount of market power. Further evidence of this comes from the failure to find a significant relationship between physician density and fees, incomes, or quantity of services provided. If there were a significant degree of competition in health care markets, one would expect variation in the number of competitors to prompt changes in at least some of these variables. 


\section{References}

Baker, Laurence C., "Can Managed Care Control Health Care Costs: Evidence From The Medicare Experience," mimeo, Princeton University, February 1994.

Bergsten, Christopher D., and Susan E. Palsbo, "HMO Market Penetration in the 54 Largest Metropolitan Statistical Areas, 1991," The Group Health Association of America, Washington DC, Research April 1993.

Bound, John, David A. Jaeger, and Regina Baker, "The Cure Can be Worse Than the Disease: a Cautionary Tale Regarding Instrumental Variables, " NBER Technical Paper No. 137, June 1993.

Office of Health Professions Analysis and Research, "User Documentation for the Area Resource File," Office of Health Professions Analysis and Research, Bureau of Health Professions, Health Resources and Services Administration, Dept. of HHS, September 1993.

Cantor, Joel C., Laurence C. Baker, and Robert G. Hughes, "Preparedness for Practice: Young Physicians' Views of their Professional Education," Journal of the American Medical Association 270:9 (September 1, 1993) 1035-1040.

Cromwell, Jerry, and Janet B. Mitchell, "Physician-Induced Demand For Surgery," The Journal of Health Economics 5 (1986) 293-313.

Evans, Robert A., "Supplier Induced Demand: Some Empirical Evidence and Implications," in The Economics of Health and Medical Care, Mark Perlman, ed., (London, McMillan, 1974).

Feldman, Roger, and Frank Sloan, "Competition Among Physicians, Revisited," Journal of Health Politics. Policy, and Law 13:2 (Summer, 1988) 239-261.

Feldman, Roger, Bryan Dowd, Don McCann, and Allan Johnson, "The Competitive Impact of Health Maintenance Organizations on Hospital Finances: an Exploratory Study," Journal of Health Politics. Policy, and Law 10:4 (Winter 1986) 675-698.

Feldstein, Paul J., Health Care Economics (Albany, NY: Delmar Inc., 1988).

Frank, Richard G., and W. Pete Welch, "The Competitive Effects of HMOs: a Review of the Evidence," Inquiry 22 (Summer, 1985) 148-161. 
Goldberg, Lawrence G., and Warren Greenberg, "The Competitive Response of Blue Cross and Blue Shield to the Growth of Health Maintenance Organizations in Northern California and Hawaii," Medical Care 17:10 (October, 1979) 1019-1028.

Goldberg, Lawrence G., and Warren Greenberg, "The Determinants of HMO Enrollment and Growth," Health Services Research 16 (1981) 421-438.

Group Health Association of America, National Directory of HMOs 1991, 1992, 1993 Washington DC: The Group Health Association of America, 1991, 1992, 1993.

Hausman, Jerry A., "Specification Tests in Econometrics," Econometrica 46:6 (November, 1978) $1251-1271$.

Hill, Steven, and Barbara Wolfe, "Testing the HMO Competitive Strategy: an Analysis of its Success and Failure in Wisconsin," mimeograph, University of Wisconsin-Madison, 1993.

Hoerger, Thomas J., "Two-part pricing and the markups charged by primary care physicians for new and established patient visits," The Journal of Health Economics 8 (1989) 399 417.

Hotelling, Harold, "Stability in Competition," Economic Journal 39 (1929) 41-57.

Luft, Harold S., and Robert H. Miller, "Patient selection in a competitive health care system," Health Affairs 7:3 (Summer 1988) 97-111.

McCarthy, Thomas R., "The Competitive Nature of the Primary-Care Physician Services Market," The Journal of Health Economics 4 (1985) 93-117.

McLaughlin, Catherine G., "The Effect of HMOs on Overall Hospital Expenses: Is Anything Left After Correcting For Simultaneity and Selectivity?" Health Services Research 23:3 (August, 1988a) 421-441.

McLaughlin, Catherine G., "Market responses to HMOs: Price Competition or Rivalry?" Inquiry 25 (Summer, 1988b) 207-218.

McNeil, Richard, and Robert E. Schlenker, "HMOs, Competition, and Government," Milbank Memorial Fund Quarterly 53:2 (Spring 1975) 195-224.

Morrisey, Michael A., and Cynthia S. Ashby, "An Empirical Analysis of HMO Market Share," Inquiry 19:2 (Summer 1982) 136-149.

Newey, Whitney, "Generalized Method of Moments Specification Testing, " Journal of Econometrics 29 (1985) 229-256. 
Newhouse, Joseph P., William B. Schwartz, Albert P. Williams, and Christina Witsberger, "Are Fee-For-Service Costs Increasing Faster Than HMO Costs?" Medical Care 23:8 (August, 1985) 960-966.

Noether, Monica, "Competition Among Hospitals," Journal of Health Economics 7 (1988) 259-284.

Palsbo, Susan E., "HMO Market Penetration in the 30 Largest Metropolitan Statistical Areas, 1989," The Group Health Association of America, Washington DC, Research Brief Number 13, December 1990.

Pauly, Mark V., and Mark A. Satterthwaite, "The Pricing of Primary Care Physicians' Services: A Test of the Role of Consumer Information," Bell Joumal of Economics $12: 2$ (1981) 488-506.

Phelps, Charles E., Health Economics (New York, NY: Harper Collins, 1992).

Reinhardt, Uwe E., "The Theory of Physician-Induced Demand: Reflections After a Decade," Journal of Health Economics 4 (1985) 187-193.

Robinson, James C., "HMO Market Penetration and Hospital Cost Inflation in California," Journal of the American Medical Association 266:19 (November 20, 1991) 2719-2723.

Rossiter, Louis F., and Gail R. Wilensky, "A reexamination of the use of physician services: the role of physician-induced demand, "Inquiry 20:2 (1983) 162-72.

Schwartz, A., and L.L. Wilde, "Imperfect Information, Monopolistic Competition, and Public Policy," American Economic Review 72:2 (May, 1982) 18-23.

Sloan, Frank and Roger Feldman, "Competition Among Physicians," in Competition in the Health Care Sector: Past. Present. and Future ed. Warren Greenberg (Germantown, MD: Aspen Systems, 1978).

Tirole, Jean, The Theory of Industrial Organization (Cambridge, MA: MIT Press, 1990).

Welch, W. Pete, "HMO enrollment: a study of market forces and regulations," Lournal of Health Politics. Policy, and Law 8:4 (1984) 743-58.

White, H., "A Heteroskedasticity-Consistent Covariance Matrix Estimator and a Direct Test for Heteroskedasticity, "Econometrica 50 (1982) 483-499.

Wilensky, Gail R. and Louis F. Rossiter, "Patient self-selection in HMOs, "Health Affairs 5:1 (Spring 1986) 66-80. 


\section{Appendix A: Derivation of Equations (8) and (9)}

This derivation follows that shown in Tirole 1990, page 279-280, and differs in the use of linear transportation costs and the assumption of separate marginal cost functions.

The unit interval, with FFS and HMO providers at opposite ends, will be split between FFS providers and HMOs at point $\mathrm{x}$, given by the solution to:

$$
P_{f}+t x=P_{h}+t(1-x)
$$

Thus demand curves as a function of the two prices are given by

$$
D_{f}=\left(P_{h}-P_{f}+t\right) / 2 t
$$

and

$$
D_{h}=\left(P_{f}-P_{h}+t\right) / 2 t
$$

Each maximizes profits, given by:

$$
\Pi_{f}=\left(P_{f}-c_{f}\right) D_{f}
$$

and

$$
\Pi_{h}=\left(P_{h}-c_{h}\right) D_{h} .
$$

The two first order conditions imply that:

$$
P_{f}=(1 / 2)\left(P_{h}+t+c_{f}\right)
$$

and 


$$
P_{h}=(1 / 2)\left(P_{f}+t+c_{h}\right)
$$

These may be solved jointly to yield the Nash equilibrium prices:

$$
\begin{aligned}
& p_{f}=t+(2 / 3) c_{f}+(1 / 3) c_{h} \\
& p_{h}=t+(2 / 3) c_{h}+(1 / 3) c_{f}
\end{aligned}
$$


Table 1: Correlation Matrices for Apportionment Methods

\begin{tabular}{|c|c|c|c|}
\hline & Series A & Series B & series $C$ \\
\hline \multicolumn{4}{|l|}{ Encollment } \\
\hline Series A & 1.000 & 0.994 & 0.992 \\
\hline Series B & 0.994 & 1.000 & 0.999 \\
\hline Series C & 0.992 & 0.999 & 1.000 \\
\hline \multicolumn{4}{|c|}{ Market Share } \\
\hline Series A & 1.000 & 0.989 & 0.977 \\
\hline Series B & 0.989 & 1.000 & 0.994 \\
\hline Series C & 0.977 & 0.994 & 1.000 \\
\hline
\end{tabular}

$\mathrm{N}=3080$ counties 
Table 2: Comparison of MSA Level Estimates Based on the New Series to the GHAA's MSA Estimates

\section{Means}

\begin{tabular}{|c|c|c|}
\hline & \multicolumn{2}{|c|}{ MSA Sample Year } \\
\hline & 1989 & 1991 \\
\hline \multicolumn{3}{|l|}{ Enroliment } \\
\hline GHAA Estimates & 906,728 & 618,253 \\
\hline Series $A$ & 927,688 & 542,984 \\
\hline Series $B$ & 943,725 & 553,545 \\
\hline Series $C$ & 949,285 & 557,245 \\
\hline \multicolumn{3}{|l|}{ Market share } \\
\hline GHAA Estimates & 21.1 & 21.8 \\
\hline Series A & 20.1 & 18.4 \\
\hline Series B & 20.5 & 18.9 \\
\hline Series $C$ & 20.7 & 19.1 \\
\hline
\end{tabular}

II. Cerrelations

GHAA MSA Estimates From

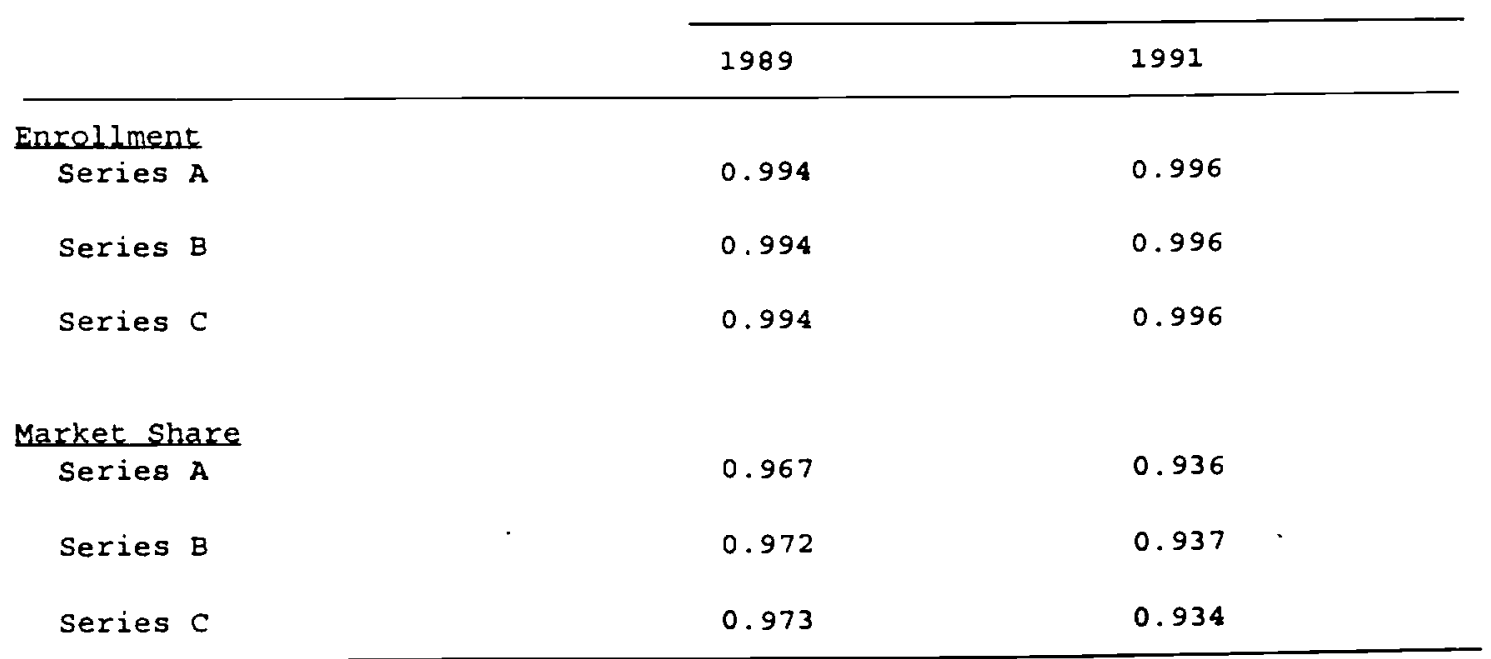

Note: The GHAA 1989 sample contains enrollment and market share estimates for 27 MSAs; the 1991 sample contains estimates for 54 MSAs. 
Table 3: Sample characteristics

\begin{tabular}{|c|c|c|}
\hline Variable & Mean & $\begin{array}{l}\text { Standard } \\
\text { Deviation }\end{array}$ \\
\hline \multicolumn{3}{|l|}{ Dependent Variable } \\
\hline Fee & 46.25 & 30.33 \\
\hline $\log ($ Fee $)$ & 3.712 & 0.490 \\
\hline \multicolumn{3}{|l|}{ Independent Vartablea } \\
\hline HMO Market Share (Series B) & 15.382 & 11.681 \\
\hline \multicolumn{3}{|l|}{ Specialty } \\
\hline General/Family Practice & 0.213 & 0.410 \\
\hline General Internal Medicine & 0.230 & 0.421 \\
\hline Spec. Internal Medicine & 0.058 & 0.234 \\
\hline General Surgery & 0.059 & 0.236 \\
\hline Specialized surgery & 0.140 & 0.347 \\
\hline Pediatrics & 0.105 & 0.306 \\
\hline Obstetrics/Gynecology & 0.087 & 0.282 \\
\hline Emergency Medicine & 0.036 & 0.185 \\
\hline other specialty & 0.072 & 0.258 \\
\hline \multicolumn{3}{|l|}{ setting } \\
\hline Self Employed Solo & 0.291 & 0.454 \\
\hline Self Employed Non Solo & 0.359 & 0.480 \\
\hline Employee of Phys. or Group & 0.141 & 0.348 \\
\hline Employee of Hospital/Clinic & 0.104 & 0.305 \\
\hline Academia & 0.079 & 0.270 \\
\hline Government & 0.012 & 0.109 \\
\hline other & 0.015 & 0.120 \\
\hline Male & 0.777 & 0.417 \\
\hline Board Certified & 0.828 & 0.377 \\
\hline International Medical Grad. & 0.138 & 0.345 \\
\hline Fes Managed Care Contract & 0.723 & 0.448 \\
\hline Age & 36.937 & 2.873 \\
\hline $\mathrm{Age}^{2}$ & 1372.554 & 212.698 \\
\hline Patients per Hour & 2.150 & 1.588 \\
\hline \multicolumn{3}{|l|}{ Area characteristics } \\
\hline MSA & 0.842 & 0.364 \\
\hline Generalists per 1000 Pop. & 0.879 & 0.536 \\
\hline Specialists per 1000 Pop. & 1.887 & 1.567 \\
\hline Hospital Beds per 1000 Pop. & 5.615 & 3.477 \\
\hline - Population High School Grad. & 54.247 & 6.341 \\
\hline Population College Grad. & 22.443 & 8.034 \\
\hline Unemployment Rate & 6.519 & 2.082 \\
\hline Per Capita Income /100Q & 19.809 & 4.989 \\
\hline - Population Female & 51.415 & 1.226 \\
\hline f Population Non-White & 20.434 & 15.447 \\
\hline Population over 65 & 12.512 & 3.488 \\
\hline \multicolumn{3}{|l|}{ Inatrumenta } \\
\hline Employees per Firm & 15.849 & 3.716 \\
\hline - workers White-collar & 59.877 & 8.670 \\
\hline
\end{tabular}

Note: Results are weighted using sampling weights. $N=2,845$. 
Table 4: First Stage Regression Results

dependent variable: HMO market share (S)

\begin{tabular}{|c|c|c|}
\hline Variable & (1) & (2) \\
\hline \multirow[t]{2}{*}{ Employees per Firm } & 0.096 & 0.055 \\
\hline & $(0.006)$ & $(0.005)$ \\
\hline \multirow[t]{2}{*}{ * Workers white-Collar } & 0.024 & 0.025 \\
\hline & $(0.006)$ & $(0.004)$ \\
\hline \multicolumn{3}{|l|}{ Generalists } \\
\hline \multirow[t]{2}{*}{ Generalists per 1000 Pop. } & 1.295 & 0.497 \\
\hline & $(0.157)$ & $(0.110)$ \\
\hline \multirow[t]{2}{*}{ Specialists per 1000 Pop. } & -0.406 & -0.328 \\
\hline & $(0.054)$ & $(0.037)$ \\
\hline \multicolumn{3}{|l|}{ specialists } \\
\hline \multirow[t]{2}{*}{ Generalists per 1000 Pop. } & 1.872 & 0.903 \\
\hline & $(0.183)$ & $(0.129)$ \\
\hline \multirow[t]{2}{*}{ specialists per 1000 Pop. } & -0.608 & -0.447 \\
\hline & $(0.066)$ & $(0.046)$ \\
\hline \multicolumn{3}{|l|}{ Specialty } \\
\hline \multirow[t]{2}{*}{ General Internal Medicine } & -0.062 & 0.050 \\
\hline & $(0.054)$ & $(0.036)$ \\
\hline \multirow[t]{2}{*}{ Spec. Internal Medicine } & -0.049 & -0.014 \\
\hline & $(0.107)$ & $(0.071)$ \\
\hline \multirow[t]{2}{*}{ General surgery } & -0.144 & -0.124 \\
\hline & $(0.106)$ & $(0.071)$ \\
\hline \multirow[t]{2}{*}{ Specialized Surgery } & -0.183 & -0.126 \\
\hline & $(0.092)$ & $(0.061)$ \\
\hline \multirow[t]{2}{*}{ Pediatrics } & 0.042 & 0.060 \\
\hline & $(0.066)$ & $(0.044)$ \\
\hline \multirow[t]{2}{*}{ Obstetrics/Gynecology } & -0.159 & -0.058 \\
\hline & $(0.100)$ & $(0.066)$ \\
\hline \multirow[t]{2}{*}{ Emergency Medicine } & -0.043 & 0.026 \\
\hline & $(0.121)$ & $(0.081)$ \\
\hline \multirow[t]{2}{*}{ Other specialty } & -0.088 & -0.116 \\
\hline & $(0.104)$ & $(0.069)$ \\
\hline
\end{tabular}

continued 
Table 4, continued

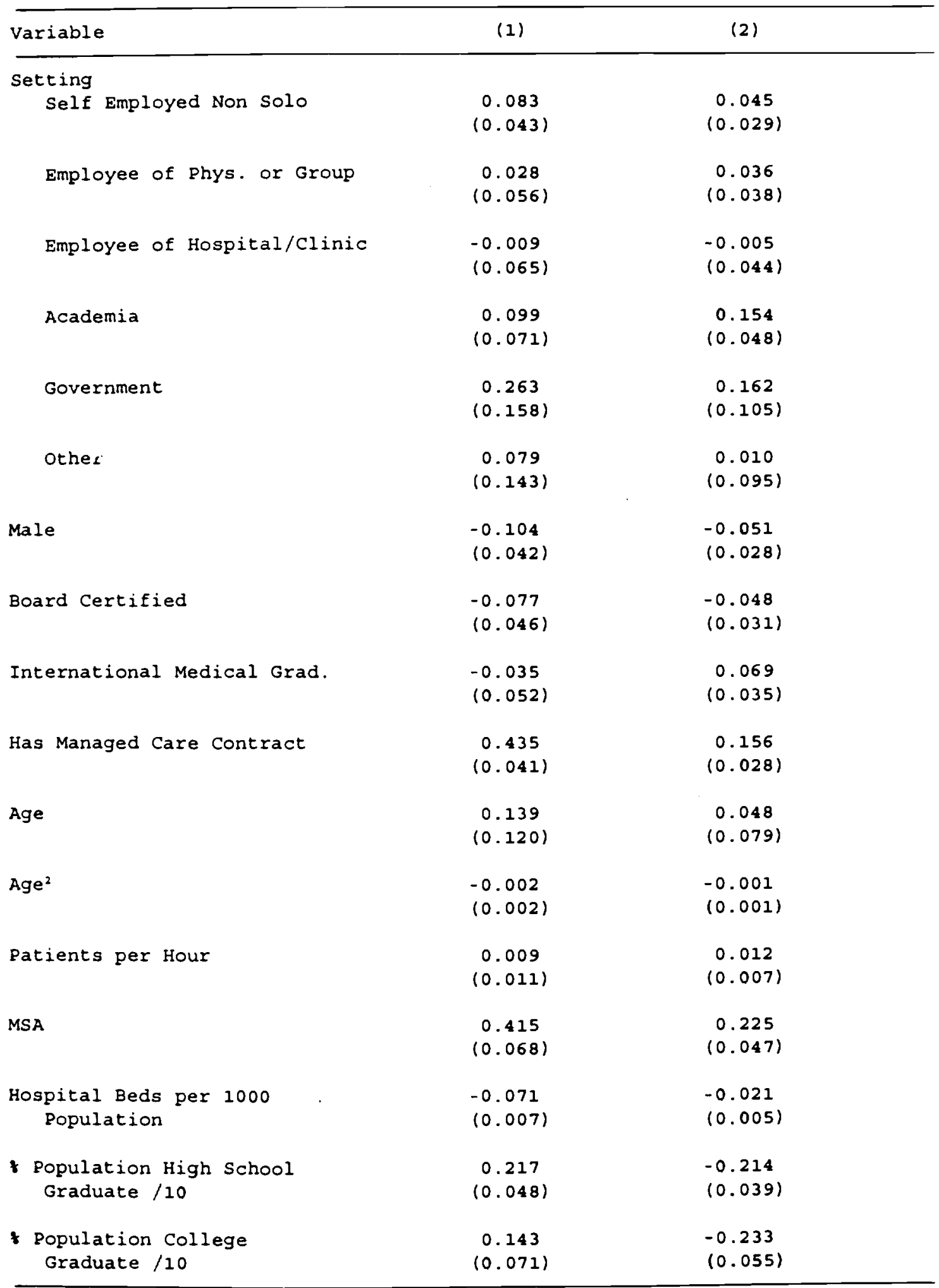

continued 
Table 4, continued

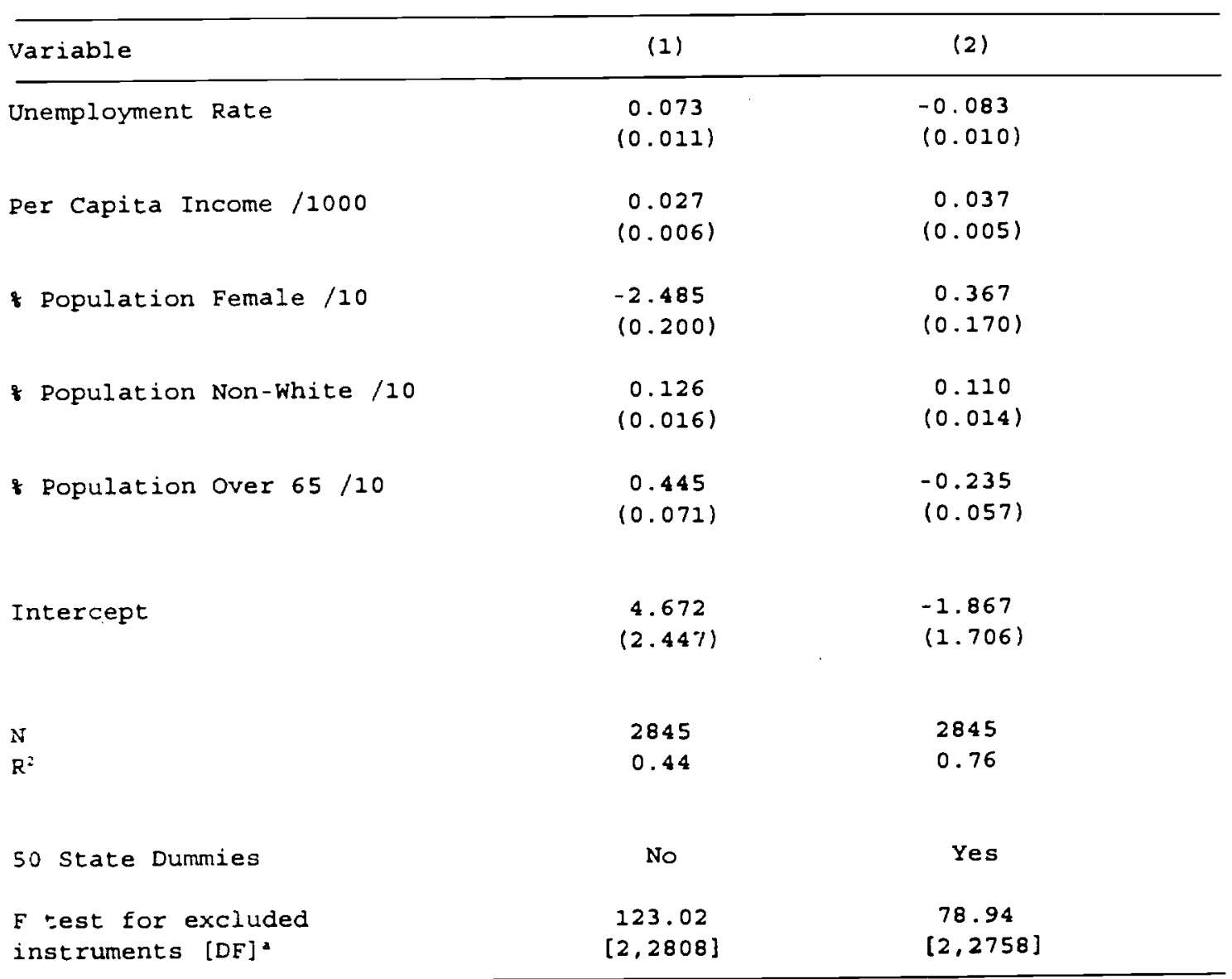

Note: Standard errors in parentheses. Results are weighted using sampling weights.

The F statistic tests the hypothesis that the coefficients on employees per firm and percent workers white collar are jointly zero. 
Table 5: OLS and 2SLS Regression Results for Fees dependent variable: $\log (f e e)$

\begin{tabular}{|c|c|c|c|c|}
\hline Variable & $\begin{array}{l}\text { OLS } \\
(1)\end{array}$ & $\begin{array}{l}2 \text { SLS } \\
(2)\end{array}$ & $\begin{array}{l}\text { OLS } \\
(3)\end{array}$ & $\begin{array}{l}2 S L S \\
(4)\end{array}$ \\
\hline HMO Market Share /10 & $\begin{array}{c}0.013 \\
(0.009)\end{array}$ & $\begin{array}{l}-0.108 \\
(0.031)\end{array}$ & $\begin{array}{l}0.005 \\
(0.013)\end{array}$ & $\begin{array}{l}-0.077 \\
(0.057)\end{array}$ \\
\hline $\begin{array}{l}\text { Generalists } \\
\quad \text { Generalists per } 1000 \text { Pop. }\end{array}$ & $\begin{array}{l}-0.058 \\
(0.074)\end{array}$ & $\begin{array}{c}0.089 \\
(0.085)\end{array}$ & $\begin{array}{l}-0.041 \\
(0.077)\end{array}$ & $\begin{array}{l}-0.011 \\
(0.080)\end{array}$ \\
\hline Specialists per 1000 Pop. & $\begin{array}{l}0.079 \\
(0.025)\end{array}$ & $\begin{array}{c}0.041 \\
(0.028)\end{array}$ & $\begin{array}{l}0.071 \\
(0.026)\end{array}$ & $\begin{array}{l}0.050 \\
(0.030)\end{array}$ \\
\hline $\begin{array}{l}\text { Specialists } \\
\text { Generalists per } 1000 \text { Pop. }\end{array}$ & $\begin{array}{l}-0.043 \\
(0.087)\end{array}$ & $\begin{array}{l}0.193 \\
(0.108)\end{array}$ & $\begin{array}{l}-0.050 \\
(0.092)\end{array}$ & $\begin{array}{l}0.019 \\
(0.103)\end{array}$ \\
\hline Specialists per 1000 POp. & $\begin{array}{l}0.059 \\
(0.031)\end{array}$ & $\begin{array}{l}-0.010 \\
(0.036)\end{array}$ & $\begin{array}{l}0.060 \\
(0.032)\end{array}$ & $\begin{array}{l}0.027 \\
(0.040)\end{array}$ \\
\hline $\begin{array}{l}\text { Specialty } \\
\text { General Internal Medicine }\end{array}$ & $\begin{array}{c}0.116 \\
(0.025)\end{array}$ & $\begin{array}{c}0.119 \\
(0.026)\end{array}$ & $\begin{array}{c}0.113 \\
(0.025)\end{array}$ & $\begin{array}{c}0.121 \\
(0.026)\end{array}$ \\
\hline Spec. Internal Medicine & $\begin{array}{c}0.229 \\
(0.050)\end{array}$ & $\begin{array}{c}0.228 \\
(0.052)\end{array}$ & $\begin{array}{c}0.244 \\
(0.050)\end{array}$ & $\begin{array}{c}0.245 \\
(0.050)\end{array}$ \\
\hline General Surgery & $\begin{array}{c}0.086 \\
(0.050)\end{array}$ & $\begin{array}{c}0.072 \\
(0.052)\end{array}$ & $\begin{array}{c}0.100 \\
(0.050)\end{array}$ & $\begin{array}{c}0.091 \\
(0.050)\end{array}$ \\
\hline Specialized Surgery & $\begin{array}{c}0.248 \\
(0.043)\end{array}$ & $\begin{array}{c}0.231 \\
(0.045)\end{array}$ & $\begin{array}{c}0.254 \\
(0.043)\end{array}$ & $\begin{array}{c}0.246 \\
(0.044)\end{array}$ \\
\hline Pediatrics & $\begin{array}{c}0.095 \\
(0.031)\end{array}$ & $\begin{array}{c}0.105 \\
(0.032)\end{array}$ & $\begin{array}{c}0.091 \\
(0.031)\end{array}$ & $\begin{array}{c}0.098 \\
(0.032)\end{array}$ \\
\hline Obstetrics/Gynecology & $\begin{array}{c}0.429 \\
(0.047)\end{array}$ & $\begin{array}{c}0.414 \\
(0.049)\end{array}$ & $\begin{array}{c}0.434 \\
(0.047)\end{array}$ & $\begin{array}{c}0.432 \\
(0.047)\end{array}$ \\
\hline Emergency Medicine & $\begin{array}{c}0.384 \\
(0.057)\end{array}$ & $\begin{array}{c}0.380 \\
(0.059)\end{array}$ & $\begin{array}{c}0.393 \\
(0.057)\end{array}$ & $\begin{array}{c}0.391 \\
(0.057)\end{array}$ \\
\hline Other Specialty & $\begin{array}{c}0.386 \\
(0.049)\end{array}$ & $\begin{array}{c}0.382 \\
(0.050)\end{array}$ & $\begin{array}{c}0.391 \\
(0.048)\end{array}$ & $\begin{array}{c}0.384 \\
(0.049)\end{array}$ \\
\hline
\end{tabular}

continued 
Table 5, continued

\begin{tabular}{|c|c|c|c|c|}
\hline Variable & $\begin{array}{l}\text { OLS } \\
\text { (1) }\end{array}$ & $\begin{array}{l}2 \text { SLS } \\
(2)\end{array}$ & $\begin{array}{l}\text { OLS } \\
(3)\end{array}$ & $\begin{array}{r}2 S L S \\
(4)\end{array}$ \\
\hline \multicolumn{5}{|l|}{ Setting } \\
\hline \multirow[t]{2}{*}{ Self Employed Non Solo } & 0.011 & 0.023 & 0.017 & 0.022 \\
\hline & $(0.020)$ & $(0.021)$ & $(0.020)$ & $(0.021)$ \\
\hline \multirow[t]{2}{*}{ Employee of Fhys. or Group } & 0.041 & 0.049 & 0.047 & 0.051 \\
\hline & $(0.027)$ & $(0.028)$ & $(0.027)$ & $(0.027)$ \\
\hline \multirow[t]{2}{*}{ Empioyee of Hospital/clinic } & 0.075 & 0.091 & 0.090 & 0.094 \\
\hline & $(0.030)$ & $(0.032)$ & $(0.031)$ & $(0.031)$ \\
\hline \multirow[t]{2}{*}{ Academia } & 0.081 & 0.100 & 0.089 & 0.103 \\
\hline & $(0.034)$ & $(0.035)$ & $(0.034)$ & $(0.035)$ \\
\hline \multirow[t]{2}{*}{ Government } & -0.344 & -0.304 & -0.350 & -0.335 \\
\hline & $(0.074)$ & $(0.078)$ & $(0.074)$ & $(0.075)$ \\
\hline \multirow[t]{2}{*}{ Other } & -0.269 & -0.268 & -0.254 & -0.258 \\
\hline & $(0.067)$ & $(0.069)$ & $(0.067)$ & $(0.067)$ \\
\hline \multirow[t]{2}{*}{ Male } & 0.008 & -0.004 & 0.009 & 0.005 \\
\hline & $(0.020)$ & $(0.021)$ & $(0.020)$ & $(0.020)$ \\
\hline \multirow[t]{2}{*}{ Board Certified } & 0.034 & 0.024 & 0.032 & 0.028 \\
\hline & $(0.022)$ & $(0.023)$ & $(0.022)$ & $(0.022)$ \\
\hline \multirow[t]{2}{*}{ International Medical Grad. } & -0.015 & -0.013 & -0.038 & -0.033 \\
\hline & $(0.025)$ & $(0.025)$ & $(0.025)$ & $(0.025)$ \\
\hline \multirow[t]{2}{*}{ Has Managed Care Contract } & 0.015 & 0.080 & 0.025 & 0.041 \\
\hline & $(0.020)$ & $(0.026)$ & $(0.020)$ & $(0.023)$ \\
\hline \multirow[t]{2}{*}{ Age } & 0.064 & 0.084 & 0.067 & 0.070 \\
\hline & $(0.056)$ & $(0.058)$ & $(0.056)$ & $(0.056)$ \\
\hline \multirow[t]{2}{*}{$\mathrm{Age}^{2}$} & -0.001 & -0.001 & -0.001 & -0.001 \\
\hline & $(0.001)$ & $(0.001)$ & $(0.001)$ & $(0.001)$ \\
\hline \multirow[t]{2}{*}{ Patients per Hour } & -0.020 & -0.018 & -0.018 & -0.017 \\
\hline & $(0.005)$ & $(0.005)$ & $(0.005)$ & $(0.005)$ \\
\hline \multirow[t]{2}{*}{ MSA } & 0.084 & 0.170 & 0.049 & 0.085 \\
\hline & $(0.028)$ & $(0.036)$ & $(0.030)$ & $(0.039)$ \\
\hline \multirow{2}{*}{$\begin{array}{l}\text { Hospital Beds per } 1000 \\
\text { population }\end{array}$} & -0.008 & -0.016 & -0.007 & -0.009 \\
\hline & $(0.003)$ & $(0.004)$ & $(0.003)$ & $(0.004)$ \\
\hline \multirow{2}{*}{$\begin{array}{l}\text { Population High School } \\
\text { Graduate / } 10\end{array}$} & -0.0002 & 0.029 & -0.008 & -0.023 \\
\hline & $(0.0216)$ & $(0.023)$ & $(0.026)$ & $(0.028)$ \\
\hline \multirow{2}{*}{$\begin{array}{c}\text { Population College } \\
\text { Gracisate / } 10\end{array}$} & -0.005 & 0.016 & -0.030 & -0.040 \\
\hline & $(0.024)$ & $(0.025)$ & $(0.027)$ & $(0.028)$ \\
\hline
\end{tabular}


Table 5, continued

\begin{tabular}{|c|c|c|c|c|}
\hline Variable & $\begin{array}{l}\text { OLS } \\
\text { (1) }\end{array}$ & $\begin{array}{l}2 \text { SLS } \\
(2)\end{array}$ & $\begin{array}{l}\text { OLS } \\
(3)\end{array}$ & $\begin{array}{l}2 \text { SLS } \\
(4)\end{array}$ \\
\hline Unemployment Rate & $\begin{array}{c}0.031 \\
(0.005)\end{array}$ & $\begin{array}{c}0.037 \\
(0.005)\end{array}$ & $\begin{array}{c}0.016 \\
(0.007)\end{array}$ & $\begin{array}{c}0.007 \\
(0.009)\end{array}$ \\
\hline Per Capita Income /1000 & $\begin{array}{c}0.021 \\
(0.003)\end{array}$ & $\begin{array}{c}0.026 \\
(0.003)\end{array}$ & $\begin{array}{c}0.015 \\
(0.004)\end{array}$ & $\begin{array}{c}0.019 \\
(0.004)\end{array}$ \\
\hline t Population Female / 10 & $\begin{array}{l}-0.383 \\
(0.088)\end{array}$ & $\begin{array}{l}-0.563 \\
(0.101)\end{array}$ & $\begin{array}{l}-0.110 \\
(0.115)\end{array}$ & $\begin{array}{l}-0.040 \\
(0.125)\end{array}$ \\
\hline Population Non-White /10 & $\begin{array}{c}0.036 \\
(0.007)\end{array}$ & $\begin{array}{c}0.055 \\
(0.009)\end{array}$ & $\begin{array}{c}0.030 \\
(0.010)\end{array}$ & $\begin{array}{c}0.043 \\
(0.013)\end{array}$ \\
\hline Population Over $65 / 10$ & $\begin{array}{c}0.043 \\
(0.032)\end{array}$ & $\begin{array}{c}0.057 \\
(0.033)\end{array}$ & $\begin{array}{c}-0.059 \\
(0.040)\end{array}$ & $\begin{array}{l}-0.093 \\
(0.046)\end{array}$ \\
\hline Intercept & $\begin{array}{c}3.454 \\
(1.146)\end{array}$ & $\begin{array}{c}3.622 \\
(1.187)\end{array}$ & $\begin{array}{c}2.484 \\
(1.201)\end{array}$ & $\begin{array}{c}2.276 \\
(1.218)\end{array}$ \\
\hline $\mathbf{N}$ & 2845 & 2845 & 2845 & 2845 \\
\hline$R^{2}$ & 0.29 & 0.24 & 0.32 & 0.31 \\
\hline 50 state Dummies & No & No & Yes & Yes \\
\hline$x^{2}[1] *$ & $-\ldots$ & 5.974 & $-\cdots$ & 0.854 \\
\hline
\end{tabular}

Note: Standard errors in parentheses. Results are weighted using sampling weights. 2SLS results use the number of employees per firm and the proportion of the workers who are white collar as excluded instruments for HMO market share.

the $x^{2}$ statistic is for a test of the overidentifying restriction. 
Table 6: 2SLS Results From Fee Regressions for Generalists and Specialists dependent variable: $\log (f e e)$

(1)

(2)

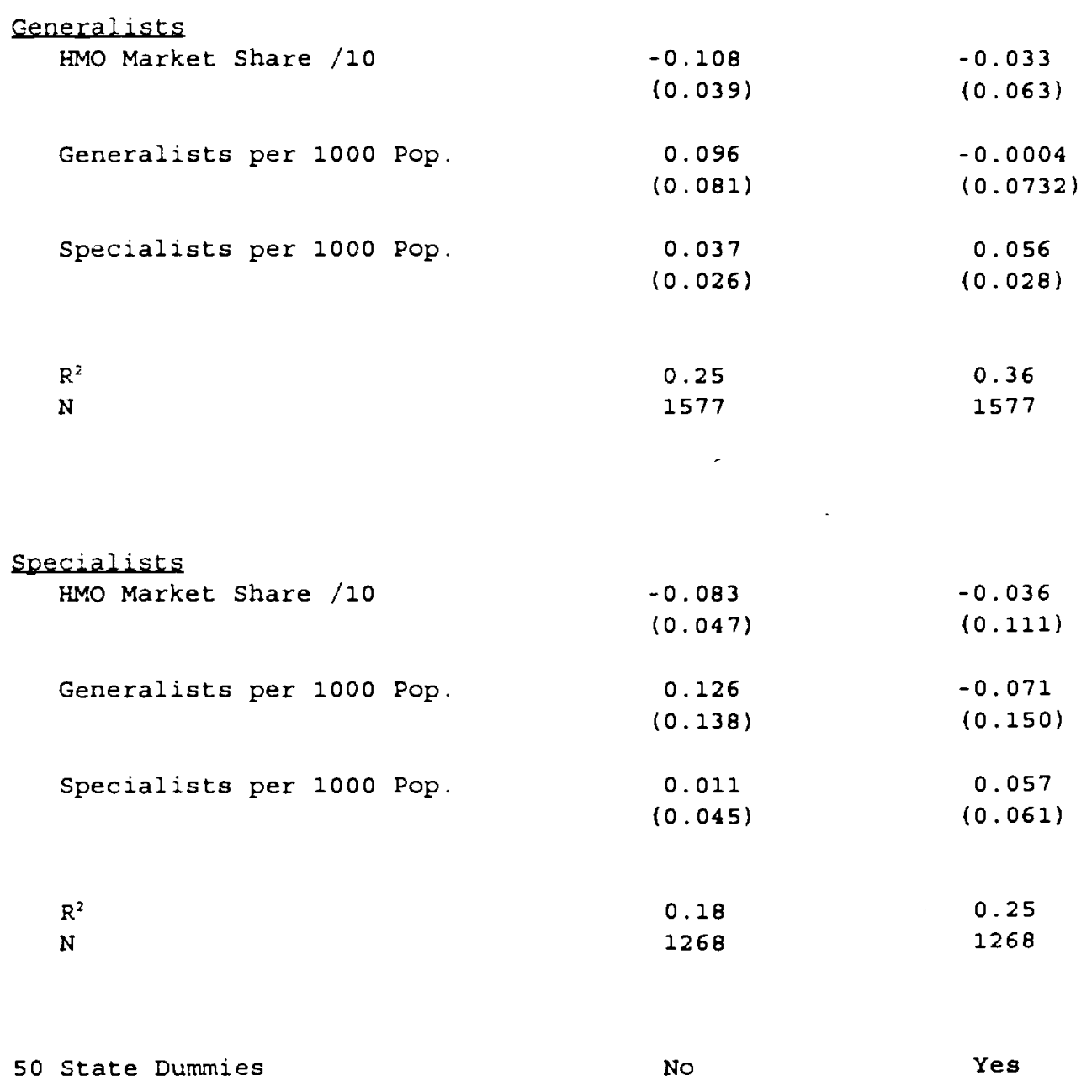

Note: Standard errors in parentheses. Results are weighted using sampling weights. The number of employees per firm and the proportion of the workers wl: 2 are white collar are excluded instruments for folo market share. Regressions also included the other covariates shown in Table 5 . 
Table 7: 2SLS Estimates from Hourly Income Equations

dependent variable: $\log$ (hourly income)

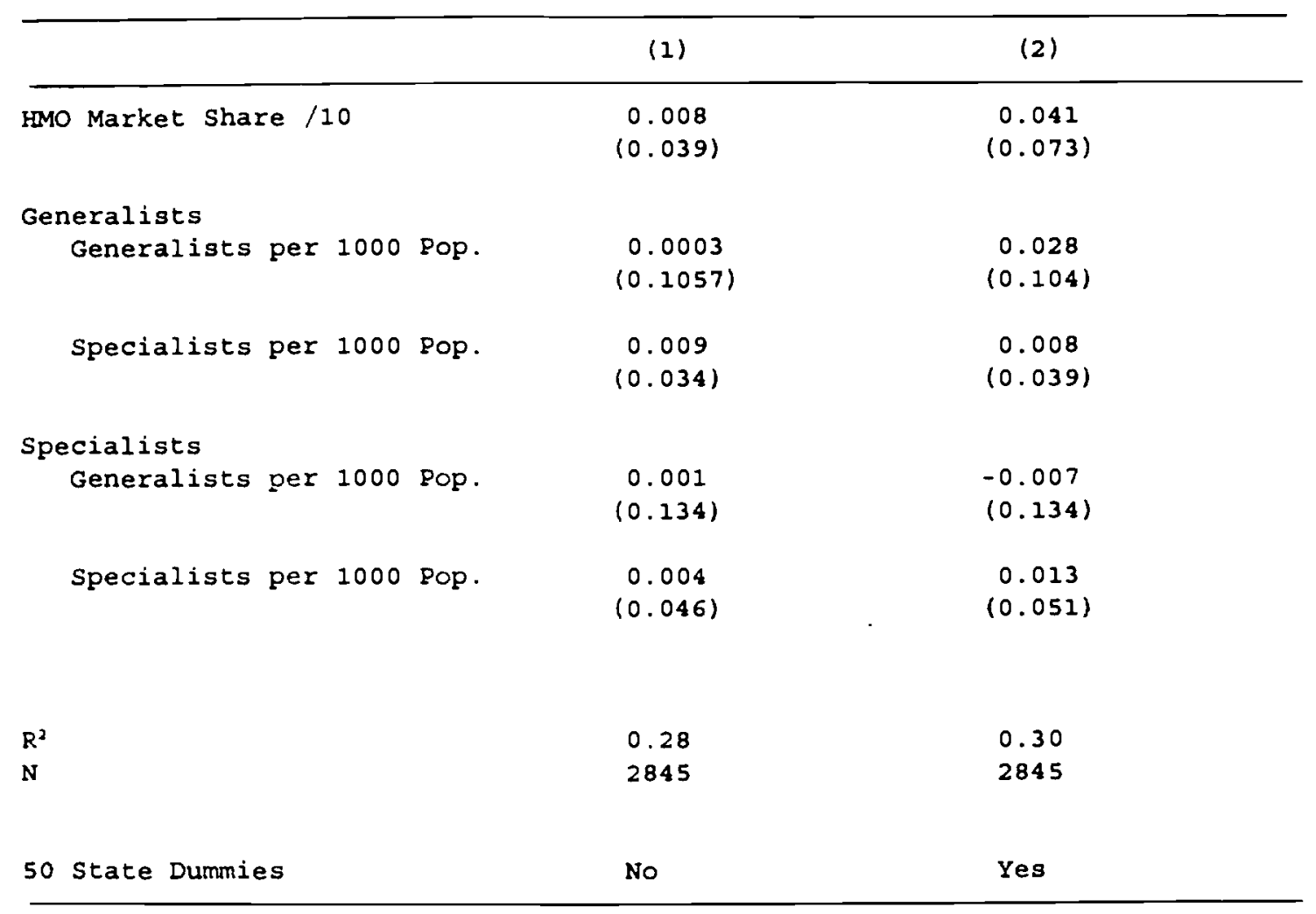

Note: Standard errors in parenthesis. Results are weighted using sampling weights. The 2 SLS estimates use the number of employees per firm and the proportion of the workers who are white collar as excluded instruments for HMO market share. Regressions also included other covariates described shown in Table 5 . 


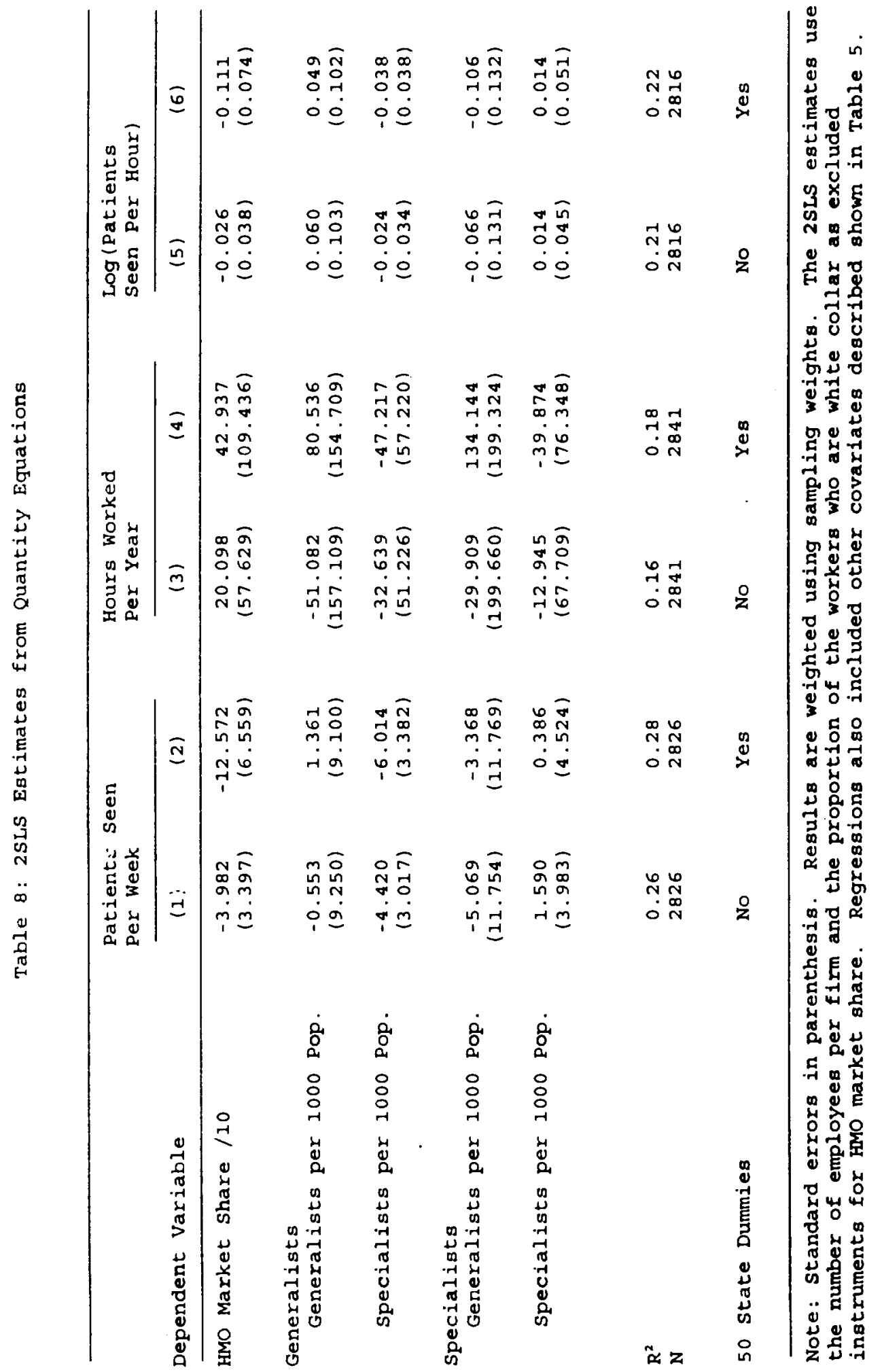


Table 9: 2SLS Estimates for Number of Surgeries Performed dependent variable: number of surgeries performed

(1)

0.444
$(0.545)$

$$
-1.724
$$$$
\text { (1.443) }
$$$$
0.578
$$$$
(0.457)
$$

$$
-0.895
$$$$
\text { (1.427) }
$$$$
0.073
$$$$
(0.488)
$$

$$
0.43
$$

1362

No
(2)

1.174
$(1.170)$

$-1.018$

(1.399)

0.647

$(0.487)$

0.367

(1.487)

$-0.089$

$(0.612)$

0.44

1362

50 State Dummies
Yes

Note: Standard errors in parenthesis. Results are weighted using sampling weights. The 2SLS estimates use the number of employees per firm and the proportion of the workers who are white collar as excluded instruments for kMo market share. Regressions also included other covariates degcribed shown in Table 5 . 


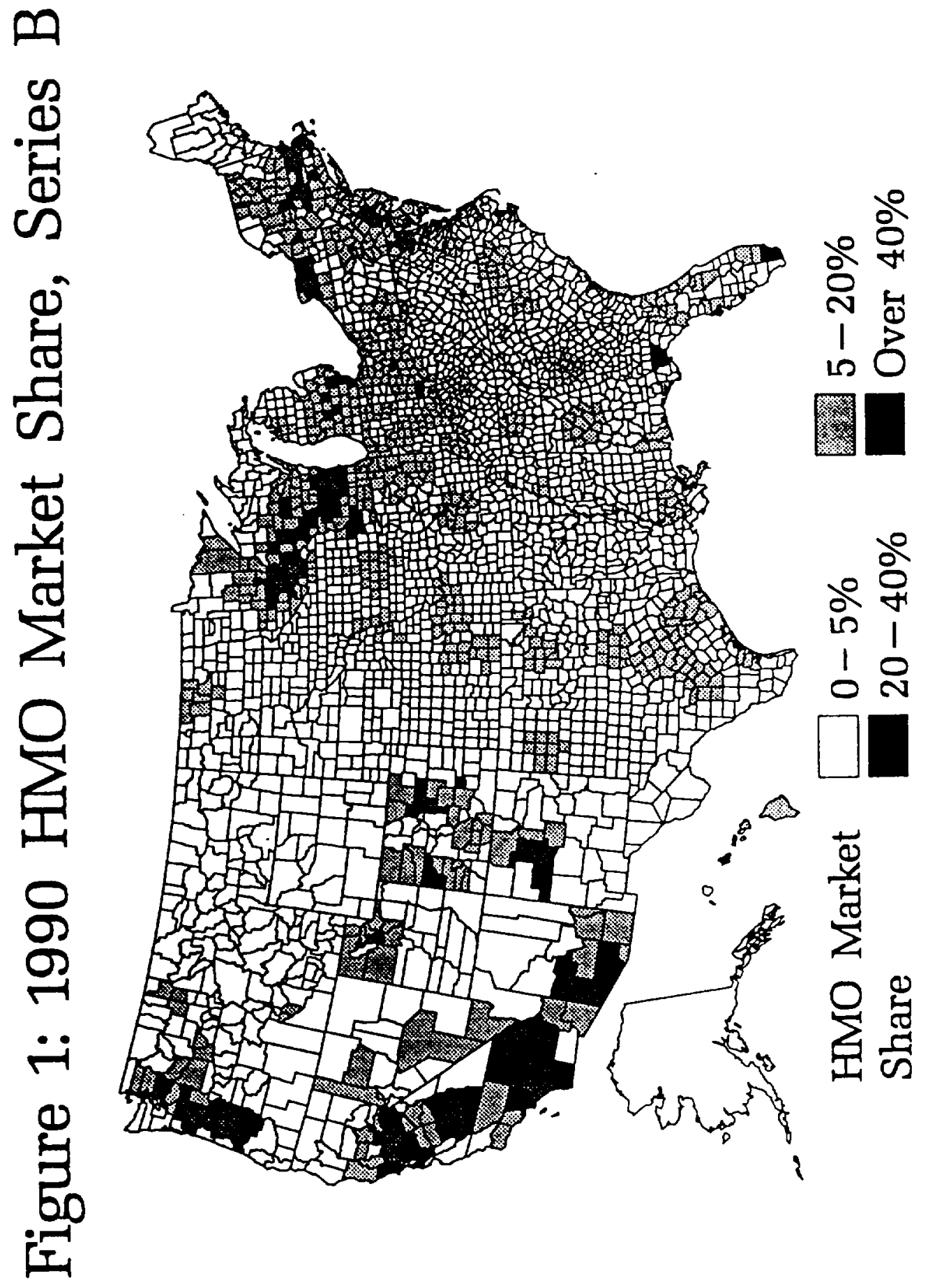

